\title{
How Can Life of Value Best Flourish in the Real World?
}

\section{Nicholas Maxwell}

\section{The Urgent Need for an Intellectual Revolution}

2. Two Fundamental Problems

3. Autobiographical Remarks

4. What Kind of Inquiry Can Best Help Life of Value to Flourish?

5. How is Life of Value Possible in the Physical Universe?

6. Connections between the Two Problems

\section{The Urgent Need for an Intellectual Revolution}

For much of my working life (from 1972 onwards) I have argued, in and out of print, that we need to bring about a revolution in the aims and methods of science - and of academic inquiry more generally. Instead of giving priority to the search for knowledge, academia needs to devote itself to seeking and promoting wisdom by rational means, wisdom being the capacity to realize what is of value in life, for oneself and others, wisdom thus including knowledge, understanding and technological know-how, but much else besides. A basic task ought to be to help humanity learn how to create a better world.

Acquiring scientific knowledge dissociated from a more basic concern for wisdom, as we do at present, is dangerously and damagingly irrational.

Natural science has been extraordinarily successful in increasing knowledge. This has been of great benefit to humanity. But new knowledge and technological know-how increase our power to act which, without wisdom, may cause human suffering and death as well as human benefit. All our modern global problems have arisen in this way: global warming, the lethal character of modern war and terrorism, threats posed by modern armaments (conventional, chemical, biological and nuclear), vast inequalities of wealth and power round the globe, rapid increase in population, destruction of tropical rain forests and other natural habitats, rapid extinction of species, even the AIDS epidemic (AIDS being spread 
by modern travel). All these distinctively modern crises have been made possible by modern science dissociated from the rational pursuit of wisdom. If we are to avoid in this century the horrors of the last one wars, death camps, dictatorships, poverty, environmental damage - we urgently need to learn how to acquire more wisdom, which in turn means that our institutions of learning become effectively, rationally, devoted to that end.

The revolution we need would change every branch and aspect of academic inquiry. A basic intellectual task of academic inquiry would be to articulate our problems of living (personal, social and global) and propose and critically assess possible solutions, possible actions, policies, political programmes, philosophies of life. This would be the task of social inquiry and the humanities. Tackling problems of knowledge would be secondary. Social inquiry would be at the heart of the academic enterprise, intellectually more fundamental than natural science. On a rather more long-term basis, social inquiry would be concerned to help humanity build cooperatively rational methods of problem-solving into the fabric of social and political life, so that we may gradually acquire the capacity to resolve our conflicts and problems of living in more cooperatively rational ways than at present. Natural science would change to include three domains of discussion: evidence, theory, and aims - the latter including discussion of metaphysics, values and politics. Pursued for its own sake, science would be more like natural philosophy, intermingling science, metaphysics and philosophy as in the time of Newton. Academic inquiry as a whole would become a kind of people's civil service, doing openly for the public what actual civil services are supposed to do in secret for governments. Academia would actively seek to educate the public by means of discussion and debate, and would not just study the public. Above all academia, internationally, would be devoted to helping humanity learn what we need to do in response to the impending crisis of global warming. The intellectual/institutional revolution, from knowledge to wisdom, that I have been arguing for, has dramatic consequences both for the internal structure and organization of academia, and for its relationship with the rest of the social world.

These changes are not arbitrary. They all come from demanding that academia cure its current structural irrationality, so that reason - the authentic article - may be devoted to promoting human welfare.

The upshot is a new kind of inquiry - wisdom-inquiry - of which natural 
science forms an integral part. Wisdom-inquiry puts into the hands of humanity, for the first time, an instrument of learning rationally designed to help us realize what is of most value to us as we live - rationally designed to help us make progress towards a good world.

Wisdom-inquiry is the solution to the profoundly important, fundamental, but much neglected philosophical problem: What kind of inquiry can best help humanity learn how to make progress towards a civilized world?

\section{Two Fundamental Problems}

Even though this is where the main effort of my working life lies, it does not sum up everything I have sought to do. Many years ago I came to the conclusion that all my work, and much of my teaching, have been concerned, in one way or another, with two fundamental, inter-related problems.

Problem 1: How can we understand our human world, embedded as it is within the physical universe, in such a way that justice is done both to the richness, meaning and value of human life on the one hand, and to what modern science tells us about the physical universe on the other hand?

Problem 2: What ought to be the overall aims and methods of science, and of academic inquiry more generally, granted that the basic task is to help humanity achieve what is of value - a wiser, more civilized world - by cooperatively rational means (it being assumed that knowledge and understanding can be of value in themselves and form a part of civilized life)?

Both problems have played a central role in the history of thought. The first problem begins with Democritus; aspects of the problem can be found in the writings of Galileo, Kepler, Boyle, Newton; it is central to the work of Descartes, Locke, Berkeley, Hume, Kant and, in more recent times, has been of concern to such diverse thinkers as Whitehead, Russell, Stebbing, Popper, Dennett, Nagel and Searle. The second problem (appropriately interpreted) occupies a central place in the thought of Socrates, Plato and Aristotle; it is basic to the work of Francis Bacon, Descartes, Locke; it has a fundamental role to play in Enlightenment thought of the 18th century; and that aspect of the problem that has to do with the pursuit of knowledge 
has continued to play a central role in philosophy and philosophy of science down to the present.

The first problem includes the mind/body problem, the problem of free will and determinism, and the problem of the relationship between facts and values; it includes problems concerning the relationship between perceptual and physical properties, and problems concerning the relationship between different branches of the sciences, from physics via biology to psychology. It involves problems concerning the interpretation of the neurosciences, Darwinian theory, and modern physical theory, especially quantum theory; and it involves questions concerning scientific realism, scientific essentialism and instrumentalism. Work that I have done on this problem includes: my MA thesis, ${ }^{1}$ my first three papers (published in 1966 and 1968), ${ }^{2}$ a series of papers on quantum theory, ${ }^{3}$ parts

${ }^{1}$ N. Maxwell, Physics and Common Sense: A Critique of Physicalism (MA thesis, Joule Library, Manchester University, 1965).

${ }^{2}$ N. Maxwell, "Physics and Common Sense", British Journal for the Philosophy of Science 16 (1966), pp. 295-311; "Can there be Necessary Connections between Successive Events?", British Journal for the Philosophy of Science 19 (1968), pp. 1-25 (reprinted in R. Swinburne, (ed.) The Justification of Induction (Oxford: Oxford University Press, 1974), pp. 149-174; "Understanding Sensations", Australasian Journal of Philosophy 46 (1968), pp. 127-146.

${ }^{3}$ In the first of these papers, published in 1972, I argued that orthodox quantum theory is seriously defective: as a result of being about measurement, the theory consists of two incompatible components, a quantum mechanical component, and a component describing measurement consisting of some part of classical physics. In order to cure this defect, I argued, all reference to measurement and "observables" needs to be removed from the postulates of the theory, precise quantum mechanical conditions being specified for probabilistic events to occur: see N. Maxwell, "A New Look at the Quantum Mechanical Problem of Measurement", American Journal of Physics 40, (1972), pp. 1431-1435. I was immediately ticked off by two American physicists for failing to understand quantum theory: see W. Band and J.L. Park, "Comments concerning "A New Look at the Quantum Mechanical Problem of Measurement", American Journal of Physics 41 (1973), pp. 1021-1022. Actually, it was Band and Park who got things wrong, as I pointed out at the time: see N. Maxwell, "The Problem of Measurement - Real of Imaginary?", American Journal of Physics 41 (1973), pp. 1022-1025. I might add that John Bell subsequently put forward a somewhat similar criticism of orthodox quantum theory from 1973 onwards: see J. Bell, Speakable and unspeakable in quantum mechanics (Cambridge: Cambridge University Press, 1987). In my paper I hoped to get across to physicists the idea that, in order to cure quantum theory of its defects, what was needed was not philosophical interpretation, but 
of What's Wrong With Science?, "Methodological Problems of Neuroscience", 5 chapter 10 of From Knowledge to Wisdom, ${ }^{6}$ and part 2 of "Induction and Scientific Realism". 7 Especially significant are: "Physics and Common Sense" (1966), chapter 10 of From Knowledge to Wisdom (1984), and "The Mind-Body Problem and Explanatory Dualism" (2000). ${ }^{8}$ The various strands of this long-standing research were brought together in my book The Human World in the Physical Universe: Consciousness, Free Will and Evolution (2001). ${ }^{9}$

straightforward physics: testable conjectures concerning the occurrence of probabilistic transitions, to be put to the test of experiment. As there was no sign of any physicist taking any interest in the idea, I struggled to develop my proposal further: see for example my "Towards a Micro Realistic Version of Quantum Mechanics", Foundations of Physics 6 (1976), pp. 275-92 and 661-76. Eventually I came up with a fully micro-realistic, fundamentally probabilistic version of quantum theory, free of the defects of, and testably distinct from, orthodox quantum theory: see my "Instead of Particles and Fields: A Micro Realistic Quantum "Smearon" Theory", Foundations of Physics 12 (1982), pp. 607-31. This was further clarified in N. Maxwell, "Quantum Propensiton Theory: A Testable Resolution of the Wave/Particle Dilemma", British Journal for the Philosophy of Science 39 (1988), pp. 1-50; and received a precise formulation in N. Maxwell, "Particle Creation as the Quantum Condition for Probabilistic Events to Occur", Physics Letters A 187 (1994), pp. 351-355. (I was prompted to develop a precise version of the theory by Euan Squires's criticism of my 1988 paper: see E. J. Squires, "A Comment on Maxwell's Resolution of the Wave/Particle Dilemma", British Journal for the Philosophy of Science 40 (1989), pp. 413-417. For my latest exposition of my fundamentally probabilistic, micro-realistic version of quantum theory see: N. Maxwell, "Is the Quantum World Composed of Propensitons?", in M. Suárez (ed.), Probabilities, Causes and Propensities in Physics, (Boston: Synthese Library, 2009).

${ }^{4}$ N. Maxwell, What's Wrong With Science?: Towards a People's Rational Science of Delight and Compassion (Hayes, UK: Bran's Head Books, 1976).

${ }^{5}$ N. Maxwell, "Methodological Problems of Neuroscience", in D. Rose and V. G. Dobson (eds.), Models of the Visual Cortex (Chichester: John Wiley, 1985), pp. 11-21.

${ }^{6}$ N. Maxwell, From Knowledge to Wisdom (Oxford: Basil Blackwell, 1984; $2^{\text {nd }}$ ed., revised throughout, new introduction and three new chapters, London: Pentire Press, 2007).

${ }^{7}$ N. Maxwell, "Induction and Scientific Realism: Einstein versus van Fraassen", British Journal for the Philosophy of Science 44 (1993), pp. 61-79, 81-101 and 275305.

${ }^{8}$ N. Maxwell, "The Mind-Body Problem and Explanatory Dualism", Philosophy 75 (2000), pp. 49-71.

${ }^{9}$ N. Maxwell, The Human World in the Physical Universe: Consciousness, Free Will 
The second problem includes standard epistemological and methodological problems about scientific progress, the rationality of science, the aims and methods of natural and social science. But it goes beyond these standard issues in embracing the whole of academic inquiry the humanities, technological research and education in addition to natural and social science - and in raising the question of how inquiry, in this broad sense, can best help people realize what is genuinely of value in life. It is very definitely not assumed that the proper intellectual aim of inquiry is knowledge. My published work on this problem began with "A Critique of Popper's Views on Scientific Method", ${ }^{10}$ and "The Rationality of Scientific Discovery". ${ }^{11}$ The first full statement of the argument for the need for a revolution, from knowledge to wisdom, is to be found in my first book What's Wrong With Science? (1976), ${ }^{12}$ it is restated, in a much more detailed and careful way in From Knowledge to Wisdom, ${ }^{13}$ and it receives a more up to date restatement in Is Science Neurotic? ${ }^{14}$ A detailed statement of the first part of the argument concerning natural science is to be found in The Comprehensibility of the Universe. ${ }^{15}$ I have also published numerous papers spelling out various aspects of the argument over the years: four examples are: "Science, Reason, Knowledge and Wisdom: A Critique of Specialism" (1980), "What Kind of Inquiry Can Best Help Us Create a Good World?" (1992), "Can Humanity Learn to become Civilized? The Crisis of Science without Civilization" (2000), and "From Knowledge to Wisdom: The Need for an Academic Revolution" (2007). ${ }^{16}$

and Evolution (Lanham, Maryland: Rowman and Littlefield, 2001).

${ }^{10}$ N. Maxwell, "A Critique of Popper's Views on Scientific Method", Philosophy of Science 39 (1972), pp. 131-52; reprinted in A. O'Hear, (ed.), Popper: Critical Assessments of Leading Philosophers, Vol. II, Part 3, (London: Routledge, 2004), pp. 463-87.

${ }^{11}$ N. Maxwell, "The Rationality of Scientific Discovery", Philosophy of Science 41 (1974), pp. 123-153 and 247-295.

${ }^{12}$ N. Maxwell, What's Wrong With Science?, op.cit.

${ }^{13}$ N. Maxwell, From Knowledge to Wisdom, op. cit.

${ }^{14}$ N. Maxwell, Is Science Neurotic? (London: Imperial College Press, 2004).

${ }^{15}$ N. Maxwell, The Comprehensibility of the Universe: A New Conception of Science (Oxford: Oxford University Press, 1998).

${ }^{16}$ N. Maxwell, "Science, Reason, Knowledge and Wisdom: A Critique of Specialism", Inquiry 23 (1980), pp. 19-81; "What Kind of Inquiry Can Best Help Us Create a Good World?, Science, Technology and Human Values 17 (1992), pp. 205-227; "Can 
In what follows I shall call the first problem the "Human World/Physical Universe Problem" (HWPhU problem), and the second the "wisdominquiry problem".

These two problems are, of course, interconnected in many ways (a point I shall return to below). The first concerns how it is possible for life of value to exist in the physical universe. The second presumes that the first has been solved and seeks to discover what kind of inquiry can best help life of value to flourish in the physical universe. Taken together, they ought, but are not, to be regarded as the fundamental problems of philosophy, embracing as they do, not just epistemology, philosophy of science and metaphysics, but also moral and political philosophy.

They may be regarded as two aspects of an even more fundamental problem: How can life of value best flourish in the real world? This is indeed, in my view, the proper basic problem, not just for philosophy, but for all of science and scholarship. It is our fundamental problem in life, practical, theoretical and conceptual, personal, social and global. Certainly all my own work has been directed towards contributing towards improving our solutions of this fundamental problem.

\section{Autobiographical Remarks}

How did I come to be preoccupied - or obsessed - with the above two problems? It goes back to my childhood.

From a young age (and probably in common with most other young children) I passionately wanted to understand. I can remember wondering, as a four-year old, how space ends. I came to the conclusion that it must end with an enormous wall. Then the awful thought occurred: What is behind the wall? I had discovered a fundamental problem of cosmology. At the same age I invented a theory as to why the sky is blue. It is blue because air is very slightly blue. I told my father about my idea, and was outraged when he seemed unconvinced. When I was six I discovered the problem of perception. I knew that when we see, light enters our eyes. This must mean, I suddenly realized, that this room I see must be inside my

Humanity Learn to become Civilized? The Crisis of Science without Civilization", Journal of Applied Philosophy 17 (2000), pp. 29-44; "From Knowledge to Wisdom: The Need for an Academic Revolution", London Review of Education, 5;2 (2007), pp. 97-115, reprinted in R. Barnett and N. Maxwell (eds.), Wisdom in the University (London: Routledge, 2008), pp. 1-19. 
head. But that is absurd: How can it possibly be inside my head? At about the same time I discovered an argument for the existence of atoms. People, animals, plants are all of a characteristic size. There must therefore, I felt rather than thought, be something in the constitution of things which makes it possible for these things to determine what size to be. Ultimately matter must be made up of atoms, of a definite size, to make it possible for familiar things to fix their size.

My parents, somewhat amused by my passion to understand, gave me a book for children about science for my eighth birthday. I discovered that it is theoretical physics which seeks to understand the ultimate nature of the universe. My task in life was clear: I would become a theoretical physicist, discover the secret of the universe (the secret of life as I then thought it to be), and reveal it to everyone. At the age of ten I devoured Penguin Science News $2,{ }^{17}$ devoted to nuclear physics and the bomb. I was fascinated and appalled. I was horrified that nuclear tests might create a hydrogen bomb out of the heavy hydrogen in the oceans, exploding the earth and everyone on it, including me. But what enthralled me was the mystery, the utter strangeness, of the universe revealed by physics, solid matter mostly empty space, velocity causing lengths to shrink and clocks to go slow, space-time not flat but curved, particles no more than waves of probability, the real world so utterly different from how we ordinarily experience it to be. To live and die and never know what sort of universe this really is struck me as the ultimate catastrophe, almost equivalent to not living at all. Nothing, nothing must divert me from the task of discovering the secret of the universe, the secret of life.

None of this, by the way, should be taken to mean that I was fiercely precocious. Not at all. In those far off days in England, 11 year olds had to take an exam which decided whether they could go on to grammar school or not. Failure more or less condemned you to leaving school without academic qualifications (unless your parents could pay for your education). I failed this crucial exam, not once, but twice! My problem was that, though not especially bright, I was insanely, pathologically intellectually ambitious.

Then, with adolescence, I began to feel it was far more important to understand people than the universe, the way to do that being via the novel. Instead of reading Jeans, Eddington, and Fred Hoyle, I plunged into the

${ }^{17}$ R.E. Peierls and J. Enogat (eds.) Science News 2 (Harmondsworth: Penguin, 1947). 
worlds of Dostoevsky, Kafka, Stendhal, Chekhov, D. H. Lawrence, Virginia Woolf and Flaubert. My real education began. I would become a novelist and dare to reveal dark secrets of the human heart no one before had dared utter. I would depict worlds with such intense imaginative power that they would seem more real than reality itself

But the educational system had stamped me science rather than humanities. Off I went to University College London to study mathematics. Earlier, I had read Eddington, and he had persuaded me that physics is really mathematics, the ultimate nature of the universe being mathematical in character. I thought I would find mathematics easy, and I would be able to devote myself to writing novels. But I was miserable, I didn't know what to write about, and I never discovered how to fabricate in order to tell the truth. And mathematics seemed both hollow and very difficult. It did not seem to be about anything - apart, that is, from analysis, which I found fascinating because it seemed to probe the foundations. I passed all my exams but, abruptly, in my second year, my grant was stopped because I had not attended enough lectures.

So I did my National Service, and became a Sergeant in the Educational Corps. And then I went to Manchester University to do Philosophy. I had failed miserably as a physicist, and as a novelist, but I was interested in philosophical problems, so I would do that for three years, and then join the grey shuffle of ordinary, uncreative life (as I then saw it).

I found I knew how to do philosophy. In our first week, Professor Arthur Prior (logician and moral philosopher) set us, as an essay subject, "Do we see stars?". When Prior gave me my essay back, he told me that he had set the subject for an open essay competition, and my essay included all the points made in the essays of the competition, but no single essay had managed to include all of mine. For my next essay, Prior asked me to read a paper in the current issue of Mind on McTaggart on time. I read it, decided the author was mistaken, and said so in my essay. "Yes, I think you're right" Prior said as he handed back my essay. I was pleased: here I was, apparently, at the coal face of philosophical research, holding my own with the philosophical professionals.

Another triumph - which I only saw as a triumph some years later came towards the end of my first year. I had to write an essay on the mind/body problem for Arthur Prior's seminar. I went for long walks in Whitworth Park (near Manchester University) in an agony of thought, and came to the conclusion that we do not ordinarily know enough about our 
inner experiences to know that they are not brain processes. In perception we see, not what is inside our heads, but what we ordinarily suppose we see, the world around us. After I had read out my essay in the seminar, Prior asked, rather sharply, what I had been reading. "Nothing", I replied. "I went for walks in Whitworth Park and thought about the problem". Prior, from New Zealand, and a friend of J. J. C. Smart, must have been somewhat startled to discover that a first year undergraduate had rediscovered for himself some of the key points made earlier in print by $U$. T. Place ${ }^{18}$ (1956) and Smart. ${ }^{19}$

But by the end of the academic year I had made myself utterly miserable, struggling hopelessly with the tangled brambles of impossible philosophical problems, locked in a nightmare of contradictory intellectual impulses. When the summer vacation came, I took a job in a factory, and in the evenings began to keep a diary, noting down my thoughts and feelings. The outcome was a series of psychic explosions which tore me apart and changed the rest of my life.

I decided that my earlier desire to be a great theoretical physicist and master the universe, and my desire to be a great novelist and master of human life, were both, when pushed to the limit of absurdity, manifestations of the desire to become God. Not only was this absurd; it was undesirable. Far more desirable was to be something that, up to then, had seemed too insignificant to deserve any consideration at all: myself. This long-neglected, fragile, worthless scrap of almost nothing now seemed to me to be, for me, the most precious thing in existence, something holy and sacrosanct. But what was it? What was I? I had no idea. Having ignored myself, in some sense, for so long, in my striving to become acquainted with, identified with, some profoundly significant otherness (ultimate physical reality, ultimate human reality), my self had become a stranger to me. It felt like a young plant, fragile from neglect and lack of nourishment, needing attention and care to grow and flourish.

When we are born, I wrote in the diary, we do not know how to distinguish "me" from "not me": there is just things happening. But then we do discover how to make the distinction, and we discover we are tiny

\footnotetext{
${ }^{18}$ U.T. Place, "Is Consciousness a Brain Process?", British Journal of Psychology, 46 (1956), pp. 44-50.

19 J.J.C. Smart, Philosophy and Scientific Realism (London: Routledge and Kegan Paul, 1963).
} 
and vulnerable in a vast, strange, and sometimes terrifying world. We falsely half remember the earlier state as a time when we were "everything", and our life project, in one way or another, becomes to return to this earlier, God-like state. One strategy is to try to convert the "not me" into "me", by conquering it, knowing and understanding it, acquiring power over it, or even literally trying to swallow it. Another standard strategy is to do just the opposite: shrink the "me" until it disappears, and there is only "everything". This is the strategy of the mystic who seeks mystical union with God; it is the strategy of the humble, and of those who commit suicide.

But both these conventional and absurd strategies rest on a mistaken view about the nature of the "me", the nature of personal identity. Our identity is not what is inside us. What lies within us is just as mysterious as what lies without us. Our identity exists in the interplay between what lies within and without. If the distinction between "me" and "not me" is depicted as a circle on a surface, the "me" is not, as we ordinarily assume, what lies within the circle; it is rather the line of the circle itself. We should not, ludicrously, try to increase the circle until, in the limit, everything is incorporated within it; nor should we, almost equally ludicrously, try to decrease the circle until it becomes a dot and disappears and there is just "everything": instead, we should "relax the muscles of identity" (as I wrote in my diary) so that the line of the circle becomes permeable, and there can be an easy interplay between what lies within and without, and we become our authentic selves, without striving to expand until, in the limit, we become everything, or shrink until we become nothing (and there is only everything).

My earlier projects to know and understand the nature of the universe by means of physics, and to know and understand humanity by means of literature, now seemed variants of the strategy to expand and expand the circle of identity. Pushed to the limits of absurdity, it was as if my ultimate aspiration had been to become God. But an infinitely more worthwhile goal lay before me, up till now neglected as worthless: to become myself. "The riddle of the universe" I wrote "is the riddle of our desires". The fundamental question of philosophy is not "How do I acquire knowledge?" but rather "What do I want? How should I live?".

These ideas, which now seem to me somewhat absurd, exaggerated and dubious at best, were for me, at the time, the stuff of my life; they were experienced and lived. Before these "revelations", I had half believed in 
Descartes' picture of the self being the mind, linked to the brain but utterly different from anything physical, the whole experienced world being locked away within the prison of one's skull. This picture was shattered. What was within was just as much a mystery as what lay without: "I" was the region of interplay between these two mysteries. I became whatever I saw or experienced, my self being created and dying many times during the day. In one of his letters, John Keats spoke of becoming the bird he saw pecking on a path. That was how it now was with me. I would be whatever I experienced: seeing a blade of grass, I became that blade of grass; talking with a friend, I became that "talking with the friend". For six weeks it was as if I was high on some hallucinatory drug: visions of exhilarating and terrifying intensity came before breakfast, and throughout the day. I had become a prophet, and my prophecy was: be your own prophet, discover for yourself your own true self, what you really desire in life.

In the end I found having a great message for the world such a contradiction that I finally hit upon the idea: there are only stories or myths. One is that of science; another is that of personal experience. Not till I read Karl Popper did I free myself of this nonsense - still so fashionable in some quarters.

I vowed that when I got back to Manchester University in the autumn, I would tell the Philosophy Department about my earth-shaking discoveries of the summer - especially, that philosophy should be about how to live, and not about how to acquire knowledge. I found I could not even open my mouth. Ecstasy gave way to persistent black despair.

I knew I had discovered something of profound importance. But what exactly? In my misery, I felt my miraculous discovery had been mislaid. I laboured to rediscover what I had lost. And very slowly, over a period of some ten to twenty years, I did rediscover and further develop my initial, slightly mad ideas. For those six weeks of ecstasy and terror are the key to all my subsequent work. What I have done since is to recoup, develop, elaborate and apply the stark, crude ideas I lived with such intensity that summer.

Looking back now, I would say that the key discovery was that "the riddle of the universe is the riddle of our desires" - or, in other words, that our aims, in science and in life, are profoundly problematic. Tied in with this was the idea that philosophy should be about how to live, not about how to acquire knowledge - and certainly not about solving conceptual problems. I generalized this, later, to become the idea that all of inquiry, 
and not just philosophy, should be about how to live - our fundamental problems being problems of living rather than problems of knowledge. Tied in with all this, too, was the discovery that the world as we experience it is as objectively real as the world revealed by theoretical physics.

Physics and literature, the two passions of my youth, each hitherto making nonsense of the other, suddenly achieved a kind of problematic synthesis in the idea that our human world and the physical universe coexist with equal reality. My struggles with physics and literature, instead of being just abject failures, became something like apprentice work for the task in hand: to bring my discovery, whatever it might be, out into the clear light of day. The roots of the human world/physical universe problem lay, for me, deep in my childhood, deep in my being.

After obtaining my degree in 1963, I decided I would devote two years to trying to capture what I had discovered, in the summer of 1961, in an MA thesis. My initial idea was to argue that there are only different stories, different myths, it being vital not to take any one story, such as that of science or common sense, too seriously. My tutor, Ted Dawson, persuaded me to restrict my attention to just two "stories", or cosmological views, that of physics and common sense.

I discovered Karl Popper, and was immensely impressed. One passage in particular made an impact:

The belief of a liberal - the belief in the possibility of a rule of law, of equal justice, of fundamental rights, and a free society - can easily survive the recognition that judges are not omniscient and may make mistakes about facts and that, in practice, absolute justice is hardly ever realized in any particular case. But this belief in the possibility of a rule of law, of justice, and of freedom, can hardly survive the acceptance of an epistemology which teaches that there are no objective facts; not merely in this particular case, but in any other case: and that the judge cannot have made a factual mistake because he can no more be wrong about the facts than he can be right. ${ }^{20}$

I found this moral argument for factual realism convincing. It made clear that to abandon the notion of factual truth is shameful, and potentially

${ }^{20}$ K. R. Popper, Conjectures and Refutations (London: Routledge and Kegan Paul, 1963), p. 5. 
disastrous. I converted my initial idea that physics and common sense are rival, equally valid stories about the nature of reality into the very different idea that they specify different aspects of reality. My task then became to pin down precisely what aspects, and how they are inter-related.

I discovered J.J.C. Smart's Philosophy and Scientific Realism, which impressed me with its clarity, simplicity and comprehensiveness - and its freedom from any hint of awful Oxford conceptual analysis. My thesis became a criticism of Smart's radical version of physicalism ("everything is made up exclusively of fundamental physical entities"). I expounded and defended a view that I have called experiential physicalism (it might be called naive realist physicalism). Physics seeks to specify only that aspect of the world which determines (perhaps probabilistically) how events unfold in time. Colours, sounds, smells, as experienced by us, exist objectively in the world, in addition to, and not reducible to, physical properties. Our inner experiences are brain processes. These have experiential features not reducible, even in principle, to physics. Understanding a person as a person is distinct from, and cannot be reduced to, scientific understanding.

The overall argument of the thesis was summarized in my first published paper "Physics and Common Sense" (1966). ${ }^{21}$ Two further papers spelled out more detailed points of my thesis: "Can there be Necessary Connections Between Successive Events?", (which specifies precisely what aspect of the world it is that physics seeks to describe, and refutes Hume on causation), and "Understanding Sensations", 2 (which spells out the "two aspect" version of the brain process theory I defend).

With the completion of my MA thesis (in 1965), and the publication of these three papers, I had completed the kernel of my solution to the problem of how it is possible for the world as we experience it to exist embedded in the physical universe, although I continued to develop further aspects of this proposed solution over the years. I expected these three papers, when published, to provoke a philosophical uproar. That they were passed over in almost complete silence left me bitterly disappointed. I came to the conclusion that publishing papers had nothing to do with communicating ideas or results, and had everything to do with promoting

\footnotetext{
${ }^{21}$ N. Maxwell, "Physics and Common Sense", op. cit.

${ }^{22}$ N. Maxwell, "Can there be Necessary Connections Between Successive Events?", op. cit.; and "Understanding Sensations", op. cit.
} 
academic careers. For a time, I stopped publishing altogether. (Some of the content of these papers did, however, receive considerable attention as a result of subsequent publications by, among others, Thomas Nagel, Frank Jackson, Fred Dretske, M. Tooley, and David Armstrong. ${ }^{23}$ However, these subsequent publications missed the most important points that I was concerned to make. Nagel and Jackson failed to appreciate that, once it is established that physics cannot predict experiential qualities as we experience them, the silence of physics about colours and other experiential qualities provides no grounds whatsoever for holding they do not exist objectively, in the world around us - in one sense of "objective" at least - a point I shall return to below. Dretske, Tooley, and Armstrong, in giving their essentialistic, anti-Humean accounts of laws, failed to explain how laws can be both necessary and empirical, which is just what my account of 1968 succeeded in doing. As I explained in my 1968 paper refuting Hume, the empirical content of an essentialistically interpreted theory lies in its existential claims; the laws are all necessary analytically, and hence not empirical.)

A year or two later, I made what I can only regard as the most important discovery of my life. Having solved the problem of how it is possible for life of value to exist in the physical universe, I was abruptly confronted with the discovery that academic inquiry must be radically transformed if it is to be rationally designed to help life of value to flourish in the physical universe.

In the next section I give an account of this discovery. In the section after, I summarize the details of my proposed solution to the first problem - the problem of how life of value is possible in the physical universe. I conclude with some remarks about interconnections between the two contributions.

\section{What Kind of Inquiry Can Best Help Life of Value to Flourish?}

A year or two after the publication of my first three papers - around 1970 -

${ }^{23}$ T. Nagel, "What Is It Like to Be a Bat?", The Philosophical Review 83 (1974), pp. 435450: F. Jackson, “What Mary Didn't Know”, Journal of Philosophy 3 (1986), pp. 29195; F. Dretske, "Laws of Nature", Philosophy of Science 44 (1977), pp. 248-68; M. Tooley, "The Nature of Law", Canadian Journal of Philosophy, 7 (1977), pp. 667-698; and D. Armstrong, A Theory of Universals (Cambridge: Cambridge University Press, 1978), and What is a Law of Nature? (Cambridge: Cambridge University Press, 1983). 
I began to wonder whether Popper really had solved the problems of induction and demarcation or, more fundamentally, the problem of exhibiting science as a rational endeavour. I came to the conclusion he had not. Popper, like almost all scientists and philosophers of science, took it for granted that the basic intellectual aim of science is to acquire knowledge of factual truth, nothing being persistently presupposed about the truth independently of evidence. But this seriously misrepresents the real aim of science. Physics persistently only accepts unified theories even though endlessly many even more empirically successful disunified rivals can always easily be concocted. This means physics makes a persistent metaphysical assumption: the universe is such that no disunified theory is true. Or, in other words: the universe is more or less physically comprehensible (only unified theories being explanatory, or depicting a physically comprehensible range of phenomena). The aim of physics is not truth per se, but rather truth presupposed to be physically comprehensible.

Popper had, in short, failed quite fundamentally to solve the problem of the rationality of science. He had failed to acknowledge the real, profoundly problematic aim of science. A new conception of science, and a new kind of science, were required which acknowledge with greater honesty the real, highly problematic aim of science of seeking explanatory truth, and which seek to improve this problematic aim as an integral part of scientific research. In order to facilitate this, the metaphysical presuppositions of science, concerning the comprehensibility and knowability of the universe, need to be represented as a hierarchy of assumptions (and associated methods), the assumptions asserting less, and thus being more likely to be true, as one ascends the hierarchy. In this way, a framework of relatively unproblematic assumptions and associated methods (aims and methods), high up in the hierarchy, is created within which much more substantial and problematic assumptions and methods can be critically assessed and improved. This new conception of science, emerging from my criticism of Popper, which I called aim-oriented empiricism, I first spelled out 1974 in a two-part paper provocatively called "The Rationality of Scientific Discovery".

Then, walking home one evening from work, it occurred to me (and I

${ }^{24}$ N. Maxwell, "The Rationality of Scientific Discovery", Philosophy of Science, 41 (1974), pp. 123-153 and 247-295. 
can remember the precise spot near Grays Inn Rd. where this thought occurred) that, taking aim-oriented empiricism as my starting point, I could tread a path parallel to that taken by Popper. Beginning with his view of science of falsificationism, Popper had generalized this to form a new conception of rationality, critical rationalism, which he had then used to make profound contributions to political philosophy and philosophy more generally, to ideas about the social sciences, to education, to a wide range of issues concerning civilization, culture, the open society. I had no doubt whatsoever of the immense importance of this line of argument of Popper, from falsificationism to critical rationalism and all the riches of his The Poverty of Historicism, Conjectures and Refutations, and above all The Open Society and Its Enemies. ${ }^{25}$

But now I had a far better starting point than Popper's. Instead of his seriously defective falsificationism, I could begin with my superior aimoriented empiricism. I could then tread a path parallel to Popper's, generalizing aim-oriented empiricism to become a new conception of rationality, aim-oriented rationality, which stresses that whenever aims are problematic, as they so often are in life and politics (and not just in science), we need to represent our aims in the form of a hierarchy so that we may improve our aims, and associated methods, as we act, as we live. And I had rediscovered my insight of the summer of 1961 - "our aims are profoundly problematic" - but in a far more powerful and general form. I now had available a heuristic scaffolding guiding the construction of my thesis and argument. All I had to do was tread a parallel path to Popper's, but because of my much improved starting point, my path would lead to much improved results.

I spelled it all out in a manuscript entitled The Aims of Science. A succession of editors at Macmillans got excited about the work, but after some four years, a new editor rejected it. Then a friend introduced me to an amateur publisher. Because of the deadline he set me, I wrote my first book, What's Wrong With Science?, published in 1976, in just three weeks. Most of it takes the form of a debate between a Philosopher and a Scientist. The Philosopher argues passionately that science misrepresents its profoundly problematic aims, and thus betrays both reason and

${ }^{25}$ K.R. Popper, The Poverty of Historicism (London: Routledge and Kegan Paul, 1961); Conjectures and Refutations, op. cit.; The Open Society and its Enemies (London: Routledge and Kegan Paul, 1969; first published 1945). 
humanity. Science needs to acknowledge problematic assumptions concerning metaphysics, values and politics inherent in the aims of science, so that these assumptions can be critically assessed and improved. The upshot is a new kind of science, and a new kind of academic inquiry more generally, which does better justice to both the intellectual and the practical aspects of inquiry.

But my "from knowledge to wisdom" argument only received its full, detailed statement eight years later with the publication of From Knowledge to Wisdom in the Orwellian year of 1984. In this book I distinguish two kinds of inquiry which I shall call here knowledge-inquiry and wisdom-inquiry. ${ }^{26}$ Both hold that a basic social or humanitarian aim of inquiry is to help promote human welfare, enhance the quality of human life, whether by intellectual or practical means.

Knowledge-inquiry, however, holds that the proper way for science, and for inquiry more generally, to pursue this social aim is, in the first, instance, to pursue the quite distinct intellectual aim of acquiring knowledge. First, knowledge is to be acquired; once acquired, it can be applied to helping solve social problems. Knowledge-inquiry restricts what can enter the intellectual domain of inquiry, in lectures and publications: a contribution must be a potential contribution to knowledge, or must contribute to the assessment of such contributions. Problems of knowledge can be discussed, but not problems of living. Proposals for action, political programmes, religious ideas, values, expressions of feelings and desires are all excluded from the intellectual domain of inquiry. This is done so that genuine, objective knowledge of fact may be acquired, and inquiry may be of genuine value to humanity. At the core of knowledge-inquiry there is a conception of science: standard empiricism. This is even more restrictive: in order to get into science, a potential contribution to knowledge must be empirically testable. The basic intellectual aim of science is taken to be knowledge of factual truth (nothing being presupposed about the truth), the basic method being to assess theories exclusively with respect to evidence (and perhaps simplicity or unity), nothing being permanently assumed about the universe independently of evidence. According to standard empiricism and knowledge-inquiry, disciplines are partially ordered in terms of how

\footnotetext{
${ }^{26}$ These conceptions and kinds of inquiry are called "the philosophy of knowledge" and "the philosophy of wisdom" in my From Knowledge to Wisdom, op cit.
} 
fundamental they are. At the most fundamental level, there is logic and mathematics; then theoretical physics, phenomenological physics and applications of physics such as astrophysics; chemistry, biology, ethnology; and then psychology and the other social sciences, with humanities such as philosophy and cultural studies as the least fundamental of all. ${ }^{27}$

Knowledge-inquiry, I argue, exercises a profound influence over almost every aspect of academic work, and is overwhelmingly the dominant conception of inquiry. Knowledge-inquiry is still almost universally accepted as the only rationalist conception of inquiry, nearly one quarter of a century after the publication of From Knowledge to Wisdom in 1984. Some academics, working in such fields as cultural studies, history of science and so-called Continental philosophy, reject both knowledgeinquiry and the whole idea of rational inquiry, influenced by doctrines such as Romanticism, the Counter-Enlightenment (as Isaiah Berlin has called it), postmodernism and social constructivism. But this is very much a dissident, minority view: almost all current academic work proceeds officially in accordance with the edicts of knowledge-inquiry. ${ }^{28}$

Despite this, knowledge-inquiry is damagingly irrational, especially when judged from the standpoint of being a kind of inquiry designed to help enhance the quality of human life. ${ }^{29}$ The successful scientific pursuit of knowledge and technological know-how dissociated from the more fundamental pursuit of wisdom is, I argue, behind all our current global crises, from global warming, the menace of modern armaments, the lethal character of modern warfare, to the destruction of tropical rainforests, rapid extinction of species, and pollution of earth, sea and air. For the sake of the future of humanity, and for the sake of inquiry itself, we urgently need to correct the damaging irrationality of knowledge-inquiry, thus creating a new kind of inquiry rationally designed to help humanity learn how to create a better world. This new kind of inquiry is what I call "wisdom-inquiry".

What do I mean by "rationality"? No more than what is required. The term "rationality", as used here, appeals to the idea that there is some, no doubt rather ill-defined, set of meta-methods, strategies or rules which, if

See my From Knowledge to Wisdom, op. cit., ch. 2.

${ }^{28}$ See Ibid., ch. 6 . See ch. 6 of the $2^{\text {nd }}$ edition for a more up-to-date account.

${ }^{29}$ Ibid., ch. 3. 
implemented, give us our best chances of solving our problems, realizing our aims. These meta-methods of reason assume there is much that we can already do, and help us marshal these actions, these already-solved problems, so as to give us the best chance of solving new problems. Rational methods do not dictate what we should do, and do not guarantee success. $^{30}$

There are two arguments designed to establish the profound structural irrationality of knowledge-inquiry, the second deepening the first. The first appeals to methods of rational problem-solving, ${ }^{31}$ the second presupposing and building on the first - to methods of rational aim pursuing when aims are problematic. ${ }^{32}$

Four elementary rules of rational problem-solving are:

(1) Articulate and seek to improve the articulation of the basic problem(s) to be solved.

(2) Propose and critically assess alternative possible solutions.

(3) When necessary, break up the basic problem to be solved into a number of specialized problems - preliminary, simpler, analogous, subordinate problems - (to be tackled in accordance with rules (1) and (2)), in an attempt to work gradually toward a solution to the basic problem to be solved.

(4) Inter-connect attempts to solve the basic problem and specialized problems, so that basic problem solving may guide, and be guided by, specialized problem solving.

Rules (1) and (2) may be regarded as encapsulating Popper's critical rationalism, arrived at by generalizing his falsificationist philosophy of science. Popper was too vehemently opposed to specialization to consider rules (3) and (4), which recognize the value of specialization and effectively deal with its dangers.

Knowledge-inquiry, we shall see, violates three of these four elementary rules of reason.

Two preliminary points. First, granted that academic inquiry has, as its fundamental aim, to help promote human welfare by intellectual and educational means, then the problems that inquiry fundamentally ought to try to help solve are problems of living, problems of action. From the

\footnotetext{
${ }^{30}$ See Ibid., $1^{\text {st }}$ ed., pp. 67-71; $2^{\text {nd }}$ ed., pp. 79-84.

${ }^{31}$ Ibid., ch. 4.

${ }^{32}$ Ibid., ch. 5.
} 
standpoint of achieving what is of value in life, it is what we $d o$, or refrain from doing, that ultimately matters. Even where new knowledge and technological know-how are relevant to the achievement of what is of value - as it is in medicine or agriculture, for example - it is always what this new knowledge or technological know-how enables us to do that matters. Second, in order to achieve what is of value in life more successfully than we do at present, we need to discover how to resolve conflicts and problems of living in more cooperatively rational ways than we do at present. There is a spectrum of ways in which conflicts can be resolved, from murder or all out war at the violent end of the spectrum, via enslavement, threat of murder or war, threats of a less extreme kind, manipulation, bargaining, voting, to cooperative rationality at the other end of the spectrum, those involved seeking, by rational means, to arrive at that course of action which does the best justice to the interests of all those involved. A basic task for a kind of academic inquiry that seeks to help promote human welfare must be to discover how conflict resolution can be moved away from the violent end of the spectrum towards the cooperatively rational end.

If inquiry put the above four rules of rational problem-solving into practice, in seeking to help promote human welfare, then it would, as a matter of absolute intellectual priority:

(1*) Articulate and seek to improve the articulation of those personal, social and global problems of living we need to solve to achieve what is of value in life (a better world).

(2*) Propose and critically assess alternative possible solutions - possible and actual cooperative actions (policies, political programmes, philosophies of life), to be assessed from the standpoint of their capacity, if implemented, to help realize what is of value in life.

Knowledge-inquiry encourages rational exploration of problems of knowledge but bans exploration of problems of living from the intellectual domain of inquiry. (Factual claims to knowledge enter the intellectual domain, but not expressions of human feelings, desires, aspirations and values, not proposals for action.) Knowledge-inquiry thus violates the two most fundamental rules of rational problem-solving conceivable (granted inquiry has the aim of helping to promote human welfare by intellectual means). $\left(1^{*}\right)$ and $\left(2^{*}\right)$ do get put into practice on the fringes of academia, as it exists at present, in departments devoted to such matters as peace, policy, the environment, politics and economics. But they are not 
intellectually fundamental, at the core of the whole academic enterprise.

Knowledge-inquiry succeeds in implementing rule (3) to splendid effect - hence the vast tree-like structure of specialized disciplines and specialized problem-solving of academia today. But, having failed to implement (1) and (2), knowledge-inquiry cannot implement (4) either. Knowledge-inquiry is so seriously irrational it violates three of the four most elementary rules of reason in a wholesale, structural manner.

This structural irrationality is no mere formal matter. It has had, and continues to have, profoundly damaging consequences. The successful pursuit of scientific knowledge and technological know-how dissociated from a more fundamental concern with problems of living, dissociated from implementation of $\left(1^{*}\right)$ and $\left(2^{*}\right)$ in other words, as required by knowledge-inquiry, has had all sorts of beneficial consequences, but has also made possible all our current global problems, such as those indicated above. Modern science and technology make possible modern armaments and the lethal character of modern warfare; they make possible modern agriculture and industry, modern medicine and hygiene, and rapid population growth, which in turn are responsible for global warming, the destruction of natural habitats and extinction of species, and the pollution of the environment. All this is to be expected. Science and technology enhance our power to act, but not our power to act wisely. If academia implemented $\left(1^{*}\right)$ and $\left(2^{*}\right)$ at a fundamental level, this would not of course guarantee that humanity would learn to resolve its problems in wiser, more cooperatively rational ways, but academia would at least be rationally designed to help humanity learn this vital lesson. Knowledge-inquiry, bereft of $\left(1^{*}\right)$ and $\left(2^{*}\right)$, is a recipe for disaster.

Failure to implement (4) has adverse consequences as well. It means that the aims, the priorities of scientific and technological research cannot be related to and influenced by sustained discussion of what our most important problems of living are, and what we need to do about them. As a result, the priorities of specialized research are likely to be influenced, not by human need, but by commercial and military pressures, and the needs of narrow specialized research interests themselves. Modern science exhibits just such tendencies.

Wisdom-inquiry (first version) emerges when knowledge-inquiry is modified just sufficiently to implement all four rules of rational problemsolving, (1) to (4). Some of the consequences of this are as follows. The intellectually central and fundamental task of wisdom-inquiry is to 


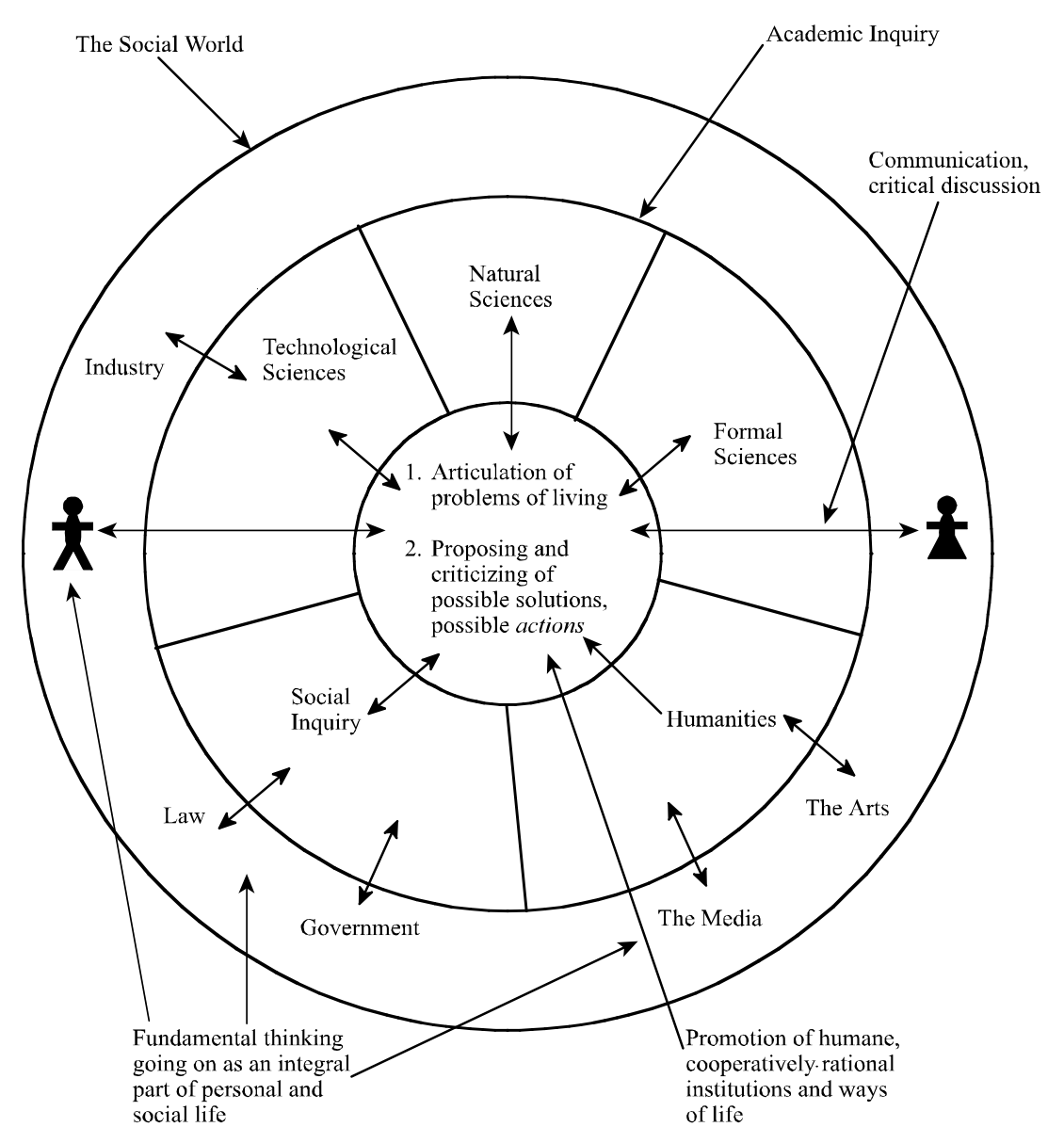

\section{Diagram 1: Wisdom-Inquiry Implementing Problem-Solving Rationality}

articulate, and improve the articulation of, those personal, social and global problems of living that need to be solved if people are to realize what is of value in life, and to propose and critically assess possible and actual actions (policies, political programmes, philosophies of life) for their capacity to help realize what is of value. This task is undertaken by social inquiry and the humanities, intellectually more fundamental than natural science. Emerging out of, and feeding back into, this intellectually fundamental activity, the natural, and technological sciences tackle secondary problems of knowledge, understanding and know-how, in accordance with rules (3) and (4). Social inquiry and humanities also, of course, seek to acquire relevant knowledge and understanding of the human world, as a secondary concern, in accordance with rules (3) and (4). 
The formal sciences, mathematics, statistics and logic, do not acquire knowledge of anything actual at all, but rather develop abstract problemsolving methods, applicable to as wide a range of circumstances as possible. Computer science and artificial intelligence straddle technology, biology, psychology and formal science. In the end, what really matters is the thinking that goes on as an integral part of personal, social and global life, guiding action. A basic task of academia is to promote the cooperative rationality of this socially active thinking. Academia is a specialized part of the social world, and needs to interact with the rest of the social world in accordance with rules (3) and (4).

The outcome of ensuring that academic inquiry puts all four rules, (1) to (4), into practice (in seeking to help promote human welfare by intellectual means) is that almost all aspects and departments of academia are changed, some quite radically. Some features of the outcome, wisdom-inquiry, are depicted in diagram 1.

It may be asked: If academia really is as grossly and damagingly irrational as the above argument would seem to indicate, when and how did this come about? My answer is that it came about as a result of the botched implementation of what may be called "The Enlightenment Programme" of learning from scientific progress how to achieve social progress towards an enlightened world. The philosophes of the French Enlightenment - Voltaire, Diderot, Condorcet and the rest - thought that this programme involved developing social science alongside natural science. This idea was further developed throughout the $19^{\text {th }}$ century by figures as diverse as Marx and Mill, and was implemented in the early $20^{\text {th }}$ century with the creation of departments of social science. The outcome was what I have been criticizing, knowledge-inquiry.

In order to implement the Enlightenment Programme properly, the following three points need to be got right:

1. The progress-achieving methods of science need to be correctly identified.

2. These methods need to be correctly generalized so that they become fruitfully applicable to any human endeavour, whatever the aims may be, and not just applicable to the endeavour of improving knowledge.

3. The correctly generalized progress-achieving methods then need to be exploited correctly in the great human endeavour of trying to make social progress towards an enlightened, wise, civilized world.

Unfortunately, the philosophes of the Enlightenment got all three points 
wrong. And as a result these blunders, undetected and uncorrected, are built into the intellectual-institutional structure of academia as it exists today. I now spell out what these blunders are, and what needs to be done to remove them. This constitutes my second argument for the urgent need to transform knowledge-inquiry into wisdom-inquiry. ${ }^{33}$

First, the philosophes failed to capture correctly the progress-achieving methods of natural science. From D'Alembert ${ }^{34}$ in the $18^{\text {th }}$ century to Popper in the $20^{\text {th }}$, the widely held view, amongst both scientists and philosophers, has been, and continues to be, that science proceeds by assessing theories impartially in the light of evidence, no permanent assumption being accepted by science about the universe independently of evidence. But this standard empiricist view is untenable. If taken literally, it would instantly bring science to a standstill. For, given any accepted theory of physics, T, Newtonian theory say, or quantum theory, endlessly many empirically more successful rivals can be concocted which agree with $\mathrm{T}$ about observed phenomena but disagree arbitrarily about some unobserved phenomena. Physics would be drowned in an ocean of such empirically more successful rival theories.

In practice, these rivals are excluded because they are disastrously disunified. Two considerations govern acceptance of theories in physics: empirical success and unity. But in persistently accepting unified theories, to the extent of rejecting disunified rivals that are just as, or even more, empirically successful, physics makes a big persistent assumption about the universe. The universe is such that all disunified theories are false. It has some kind of unified dynamic structure. It is physically comprehensible in the sense that explanations for phenomena exist to be discovered.

But this untestable (and thus metaphysical) assumption that the universe is physically comprehensible is profoundly problematic. Science is obliged to assume, but does not know, that the universe is comprehensible. Much less does it know that the universe is comprehensible in this or that way. A glance at the history of physics reveals that ideas have changed dramatically over time. In the $17^{\text {th }}$ century there was the idea that the universe consists of corpuscles, minute billiard balls, which interact only

\footnotetext{
${ }^{33}$ Ibid., ch. 5.

${ }^{34}$ J. d'Alembert, Preliminary Discourse to the Encyclopedia of Diderot (New York: Bobbs-Merrill, 1963; originally published in 1751).
} 
by contact. This gave way to the idea that the universe consists of pointparticles surrounded by rigid, spherically symmetrical fields of force, which in turn gave way to the idea that there is one unified self-interacting field, varying smoothly throughout space and time. Nowadays we have the idea that everything is made up of minute quantum strings embedded in ten or eleven dimensions of space-time. Some kind of assumption along these lines must be made but, given the historical record, and given that any such assumption concerns the ultimate nature of the universe, that of which we are most ignorant, it is only reasonable to conclude that it is almost bound to be false.

The way to overcome this fundamental dilemma inherent in the scientific enterprise - as I have already indicated - is to construe physics as making a hierarchy of metaphysical assumptions concerning the comprehensibility and knowability of the universe, these assumptions becoming progressively less substantial and thus more likely to be true, and also more nearly such that their truth is required for science, or the pursuit of knowledge, to be possible at all, as one ascends the hierarchy: see figure 2. In this way a framework of relatively insubstantial, unproblematic, fixed assumptions and associated methods is created within which much more substantial and problematic assumptions and associated methods can be critically assessed, changed, and indeed improved (partly in the light of the relative empirical success and failure of associated scientific research programmes). Put another way, a framework of relatively unspecific, unproblematic, fixed aims and methods is created within which much more specific and problematic aims and methods evolve as scientific knowledge evolves. (A basic aim of science is to discover in what precise way the universe is comprehensible, this aim evolving as assumptions about comprehensibility evolve.) Science adapts its nature to what it finds out about the universe There is something like positive feedback between improving knowledge, and improving aimsand-methods, improving knowledge-about-how-to-improve-knowledge the nub of scientific rationality, and the methodological key to the unprecedented success of modern science. ${ }^{35}$

\footnotetext{
${ }^{35}$ See N. Maxwell, "The Rationality of Scientific Discovery", op. cit.; What's Wrong With Science?, op.cit.; From Knowledge to Wisdom, op. cit., chs. 5 and 9; The Comprehensibility of the Universe, op. cit.; Is Science Neurotic?, op. cit.; "Popper, Kuhn, Lakatos and Aim-Oriented Empiricism", Philosophia, 32;1-4 (2005), pp. 181239; From Knowledge to Wisdom, $2^{\text {nd }}$ ed. (London: Pentire Press, 2007), ch. 14.
} 
Natural science has made such astonishing progress in improving knowledge and understanding of nature because it has put something like the hierarchical methodology, indicated here, into scientific practice. Officially, however, scientists continue to hold the standard empiricist view that no untestable metaphysical theses concerning the comprehensibility and knowability of the universe are accepted as a part of scientific knowledge. In Is Science Neurotic? chapter 2, I argue that science would be even more successful, in a number of ways, if scientists adopted and explicitly implemented the hierarchical methodology indicated here. ${ }^{36}$

But it is not just that there are unacknowledged, highly problematic metaphysical assumptions inherent in the aims of science; there are, in addition, unacknowledged, problematic assumptions concerning values, and politics (the human use of science). Science does not just seek explanatory truth; more generally, it seeks important truth, and this is sought so that it will be used, in one way or another, ideally to contribute to the quality of human life. These evaluative and political assumptions implicit in the aims of science are, if anything, even more profoundly problematic than the metaphysical assumptions. Here, too, problematic aims need to be represented in the form of a hierarchy, aims becoming less specific and problematic as one goes up the hierarchy, to facilitate the critical assessment and improvement of aims (and associated methods). Philosophy of science - the study of aims and methods of science becomes a vital, integral part of science itself. ${ }^{37}$

So much for the first blunder of the traditional Enlightenment, and how to put it right.

Second, having failed to identify the methods of science correctly, the philosophes naturally failed to generalize these methods properly. They failed to appreciate that the idea of representing the problematic aims (and associated methods) of science in the form of a hierarchy can be generalized and applied fruitfully to other worthwhile enterprises besides science. Many other enterprises have problematic aims - problematic because aims conflict, and because what we seek may be unrealizable, undesirable, or both. Such enterprises, with problematic aims, would

\footnotetext{
${ }^{36}$ See also my "Do We Need a Scientific Revolution?", Journal of Biological Physics and Chemistry, 8;3 (September 2008).

${ }^{37}$ From Knowledge to Wisdom, op. cit., ch. 5; Is Science Neurotic?, op. cit., ch. 2.
} 


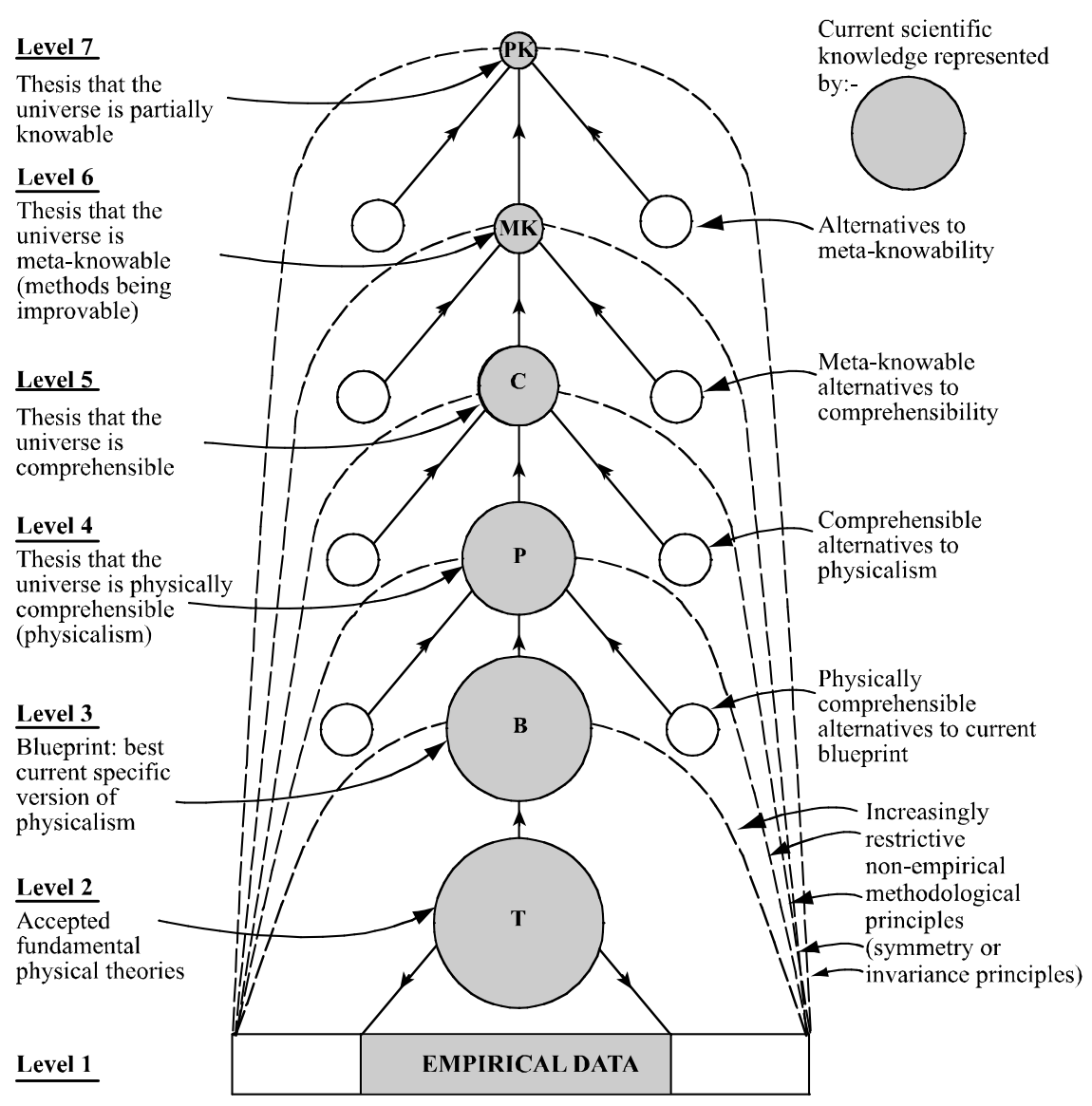

\section{Diagram 2: Hierarchical Aim-Oriented Empiricist Conception of Science}

benefit from employing a hierarchical methodology, generalized from that of science, thus making it possible to improve aims and methods as the enterprise proceeds. There is the hope that, as a result of exploiting in life methods generalized from those employed with such success in science, some of the astonishing success of science might be exported into other worthwhile human endeavours, with problematic aims quite different from those of science.

Third, and most disastrously of all, the philosophes failed completely to try to apply such generalized, hierarchical progress-achieving methods to the immense, and profoundly problematic enterprise of making social progress towards an enlightened, wise world. The aim of such an enterprise is notoriously problematic. For all sorts of reasons, what constitutes a good world, an enlightened, wise or civilized world, attainable and genuinely desirable, must be inherently and permanently 
problematic.

There are a number of ways of highlighting the inherently problematic character of the aim of creating civilization. People have very different ideas as to what does constitute civilization. Most views about what constitutes Utopia, an ideally civilized society, have been unrealizable and profoundly undesirable. People's interests, values and ideals clash. Even values that, one may hold, ought to be a part of civilization may clash. Thus freedom and equality, even though inter-related, may nevertheless clash. It would be an odd notion of individual freedom which held that freedom was for some, and not for others; and yet if equality is pursued too singlemindedly this will undermine individual freedom, and will even undermine equality, in that a privileged class will be required to enforce equality on the rest, as in the old Soviet Union. A basic aim of legislation for civilization, we may well hold, ought to be increase freedom by restricting it: this brings out the inherently problematic, paradoxical character of the aim of achieving civilization. One thinker who has stressed the inherently problematic, contradictory character of the idea of civilization is Isaiah Berlin. ${ }^{38}$ Berlin thought the problem could not be solved; I, on the contrary, hold that the hierarchical methodology indicated here provides us with the means to learn how to improve our solution to it in real life.

Here, above all, then, it is essential to employ the generalized version of the hierarchical, progress-achieving methods of science, designed specifically to facilitate progress when basic aims are problematic: see Figure 3. It is just this that the philosophes failed to do. Instead of applying the hierarchical methodology to social life, the philosophes sought to apply a seriously defective conception of scientific method to social science, to the task of making progress towards, not a better world, but to better knowledge of social phenomena. And this ancient blunder is still built into the institutional and intellectual structure of academia today, inherent in the current character of social science. ${ }^{39}$

Properly implemented, in short, the Enlightenment idea of learning from scientific progress how to achieve social progress towards an enlightened

\footnotetext{
${ }^{38}$ I. Berlin, Concepts and Categories (Oxford: Oxford University Press, 1980), pp. 74-79.

39 See my From Knowledge to Wisdom, op. cit., ch. 5; "Do Philosophers Love Wisdom?", The Philosophers' Magazine, Issue 22, $2^{\text {nd }}$ quarter (2003), pp. 22-24; Is Science Neurotic?, op. cit., ch. 3 and 4.
} 
world would involve developing social inquiry, not as social science, but as social methodology, or social philosophy. A basic task would be to get into personal and social life, and into other institutions besides that of science - into government, industry, agriculture, commerce, the media, law, education, international relations - hierarchical, progress-achieving methods (designed to improve problematic aims) arrived at by generalizing the methods of science. A basic task for academic inquiry as a whole would be to help humanity learn how to resolve its conflicts and problems of living in more just, cooperatively rational ways than at present. This task would be intellectually more fundamental than the scientific task of acquiring knowledge. Academia would have just sufficient power (but no more) to retain its independence from government, industry, the press, public opinion, and other centres of power and influence in the social world. It would seek to learn from, educate, and argue with the great social world beyond, but would not dictate. Academic thought would be pursued as a specialized, subordinate part of what is really important and fundamental: the thinking that goes on, individually, socially and institutionally, in the social world, guiding individual, social and institutional actions and life. Instead of the intellectual and humanitarian aims of science being distinct, as for knowledge-inquiry, these aims become one and the same: to help humanity acquire wisdom - wisdom being the capacity to realize (apprehend and create) what is of value in life, for oneself and others, wisdom thus including knowledge and technological know-how but much else besides.

One outcome of getting into social and institutional life the kind of aimevolving, hierarchical methodology indicated above, generalized from science, is that it becomes possible for us to develop and assess rival philosophies of life as a part of social life, somewhat as theories are developed and assessed within science. Such a hierarchical methodology provides a framework within which competing views about what our aims and methods in life should be - competing religious, political and moral views - may be cooperatively assessed and tested against broadly agreed, unspecific aims (high up in the hierarchy of aims) and the experience of personal and social life. There is the possibility of cooperatively and progressively improving such philosophies of life (views about what is of value in life and how it is to be achieved) much as theories are cooperativelyand progressively improved in science. In science, ideally, theories are critically assessed with respect to each other, with respect to metaphysical ideas 


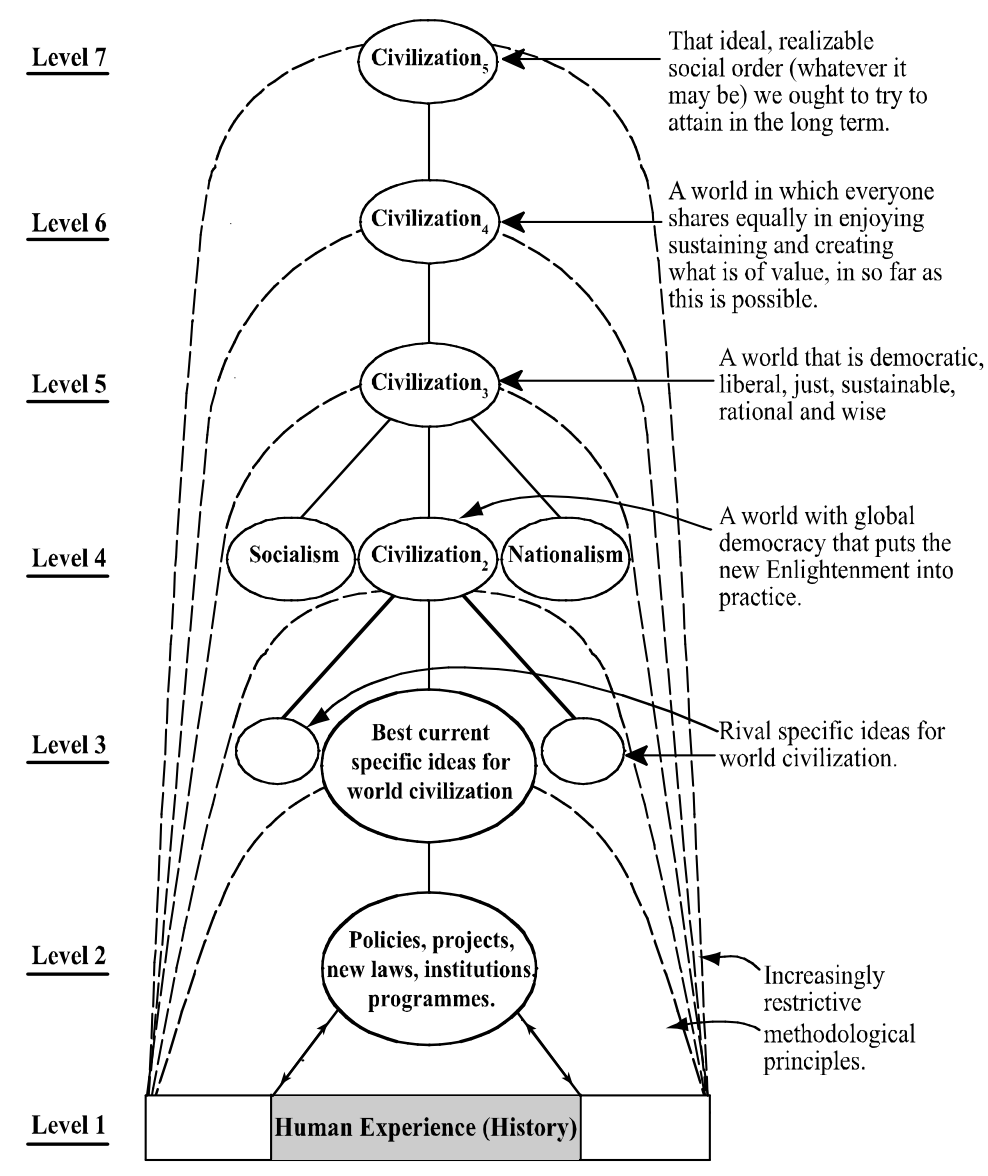

\section{Diagram 3: Hierarchical Social Methodology Generalized from Science}

concerning the comprehensibility of the universe, and with respect to experience (observational and experimental results). In a somewhat analogous way, diverse philosophies of life may be critically assessed with respect to each other, with respect to relatively uncontroversial, agreed ideas about aims and what is of value, and with respect to experience - what we do, achieve, fail to achieve, enjoy and suffer - the aim being to improve philosophies of life (and more specific philosophies of more specific enterprises within life such as government, education or art) so that they offer greater help with the realization of what is of value in life. This hierarchical methodology is especially relevant to the task of resolving conflicts about aims and ideals, as it helps disentangle agreement (high up in the hierarchy) and disagreement (more likely to be low down in the hierarchy).

Wisdom-inquiry, because of its greater rigour, has intellectual standards 
that are, in important respects, different from those of knowledge-inquiry. Whereas knowledge-inquiry demands that emotions and desires, values, human ideals and aspirations, philosophies of life be excluded from the intellectual domain of inquiry, wisdom-inquiry requires that they be included. In order to discover what is of value in life it is essential that we attend to our feelings and desires. But not everything we desire is desirable, and not everything that feels good is good. Feelings, desires and values need to be subjected to critical scrutiny. And of course feelings, desires and values must not be permitted to influence judgements of factual truth and falsity. Wisdom-inquiry embodies a synthesis of traditional rationalism and romanticism. It includes elements from both, and it improves on both. It incorporates romantic ideals of integrity, having to do with motivational and emotional honesty, honesty about desires and aims; and at the same time it incorporates traditional rationalist ideals of integrity, having to do with respect for objective fact, knowledge, and valid argument. Traditional rationalism takes its inspiration from science and method; romanticism takes its inspiration from art, from imagination, and from passion. Wisdom-inquiry holds art to have a fundamental rational role in inquiry, in revealing what is of value, and unmasking false values; but science, too, is of fundamental importance. What we need, for wisdom, is an interplay of sceptical rationality and emotion, an interplay of mind and heart, "so that we may acquire heartfelt minds, and mindful hearts" ${ }^{40}$ Wisdom-inquiry promises to heal the great rift in our culture, so graphically depicted by Snow. ${ }^{41}$

All in all, if the Enlightenment revolution had been carried through properly, the three steps indicated above being correctly implemented, the outcome would have been a kind of academic inquiry very different from what we have at present, inquiry devoted primarily to the intellectual aim of acquiring knowledge. ${ }^{42}$

A number of objections may be made to these two arguments designed to establish that knowledge-inquiry urgently needs to be transformed into wisdom-inquiry.

\footnotetext{
${ }^{40}$ N. Maxwell, What's Wrong With Science?, op. cit., p. 5.

41 C.P. Snow, The Two Cultures and a Second Look (Cambridge: Cambridge University Press, 1964).

${ }^{42}$ See my From Knowledge to Wisdom, op. cit., chs. 5 and 7; Is Science Neurotic?, op. cit., chs. 3 and 4.
} 
It may be objected that these arguments assume that a basic aim of science, of inquiry, is to help promote human welfare, knowledge being a means to that end. But this assumption may be challenged. The proper basic aim of science (or of inquiry), it may be held, is to acquire knowledge, whether this benefits humanity or not. Once this is acknowledged, the two arguments above collapse.

I have three replies. First, even if it is conceded that the proper aim of science is just knowledge, this does not tell against the decisive point that the scientific aim of acquiring knowledge makes implicit, problematic assumptions concerning metaphysics, values and politics. The idea that science seeks truth dissociated from assumptions concerning metaphysics, values and politics (the human use of science) is untenable. Once this point is acknowledged, it becomes clear that science is more rigorous intellectually if it subjects assumptions concerning metaphysics, values and politics to sustained criticism, in an attempt to improve them. Science pursued in this manner cannot be regarded as seeking knowledge dissociated from all considerations of its human value and use. Second, once it is acknowledged that problematic assumptions concerning values and politics are, inevitably, inherent in the aims and priorities of research, it becomes a matter of vital importance that academia has available intellectual/institutional means progressively to improve these assumptions. Wisdom-inquiry provides these means, whereas knowledge-inquiry does not. Finally, one may well hold that it is immoral to defend the view that science should restrict itself to seeking knowledge irrespective of its human value. There are three points to note. First, substantial public funds are devoted to supporting science in the expectation that science will benefit humanity. Given this, how can it be morally justifiable to defend a conception of science (a) which holds that any human value science has is purely incidental, and (b) which is damagingly irrational when judged from the standpoint of human value? Second, science in any case has a massive impact on society. Do not scientists have a prime responsibility to ensure that science is pursued in such a way that this impact is as good as possible? This means science should be pursued within the framework of wisdom-inquiry. Third, humanity is in deep trouble, and urgently needs to learn how to manage its affairs more wisely. It must be immoral to oppose a kind of academic inquiry rationally designed to help humanity learn this vital lesson.

Another objection that may be made to the whole argument is that it 
cannot be correct to hold that social inquiry is intellectually more fundamental than natural science. Before problems of living can be tackled, relevant knowledge must first be acquired. I have decisively refuted this orthodox view. ${ }^{43}$ Simply in order to know what is relevant, we have to have some preliminary idea about what to do in response to a problem of living. More fundamentally, action, and the capacity to act, is more fundamental than propositional knowledge. Knowing how, to use Ryle's terms, comes before knowing that.

Finally, it may be objected that wisdom-inquiry may do better justice to the practical aspects of inquiry, but does not do justice to the intellectual or cultural aspects of inquiry - inquiry pursued for its own sake. My reply, here, is that wisdom-inquiry does better justice to both aspects of inquiry, "pure" and "applied".

From the standpoint of the intellectual or cultural aspect of inquiry, what really matters is the desire that people have to see, to know, to understand, the passionate curiosity that individuals have about aspects of the world, and the knowledge and understanding that people acquire and share as a result of actively following up their curiosity. An important task for academic thought in universities is to encourage non-professional thought to flourish outside universities. As Einstein once remarked "Knowledge exists in two forms - lifeless, stored in books, and alive in the consciousness of men. The second form of existence is after all the essential one; the first, indispensable as it may be, occupies only an inferior position". ${ }^{4}$

Wisdom-inquiry is designed to promote all this in a number of ways. It does so as a result of holding thought, at its most fundamental, to be the personal thinking we engage in as we live. It does so by recognizing that acquiring knowledge and understanding involves articulating and solving personal problems that one encounters in seeking to know and understand. It does so by recognizing that passion, emotion and desire, have a rational role to play in inquiry, disinterested research being a myth. Again, as Einstein has put it "The most beautiful experience we can have is the mysterious. It is the fundamental emotion which stands at the cradle of true art and true science. Whoever does not know it and can no longer

\footnotetext{
${ }^{43}$ From Knowledge to Wisdom, op. cit., $1^{\text {st }}$ ed., pp. 171-181; $2^{\text {nd }}$ ed., pp. 194-205..

${ }^{44}$ A. Einstein, Ideas and Opinions (London: Souvenir Press, 1973; first published 1954), p. 80.
} 
wonder, no longer marvel, is as good as dead, and his eyes are dimmed". ${ }^{4}$

Knowledge-inquiry, by contrast, all too often fails to nourish "the holy curiosity of inquiry", 46 and may even crush it out altogether. Knowledgeinquiry gives no rational role to emotion and desire; passionate curiosity, a sense of mystery, of wonder, have no place, officially, within the rational pursuit of knowledge. The intellectual domain becomes impersonal and split off from personal feelings and desires; it is difficult for "holy curiosity" to flourish in such circumstances. Knowledge-inquiry hardly encourages the view that inquiry at its most fundamental is the thinking that goes on as a part of life; on the contrary, it upholds the idea that fundamental research is highly esoteric, conducted by physicists in contexts remote from ordinary life. Even though the aim of inquiry may, officially, be human knowledge, the personal and social dimension of this is all too easily lost sight of, and progress in knowledge is conceived of in impersonal terms, stored lifelessly in books and journals. Rare is it for popular books on science to take seriously the task of exploring the fundamental problems of a science in as accessible, non-technical and intellectually responsible a way as possible. (A recent, remarkable exception is Roger Penrose's The Road to Reality. ${ }^{47}$ ) Such work is not highly regarded by knowledge-inquiry, as it does not contribute to "expert knowledge". The failure of knowledge-inquiry to take seriously the highly problematic nature of the aims of inquiry leads to insensitivity as to what aims are being pursued, to a kind of institutional hypocrisy. Officially, knowledge is being sought "for its own sake", but actually the goal may be immortality, fame, the flourishing of one's career or research group, as the existence of bitter priority disputes in science indicates. Education suffers. Science students are taught a mass of established scientific knowledge, but may not be informed of the problems which gave rise to this knowledge, the problems which scientists grappled with in creating the knowledge. Even more rarely are students encouraged themselves to grapple with such problems. And rare, too, is it for students to be encouraged to articulate their own problems of understanding that must, inevitably arise in absorbing all this information, or to articulate their instinctive criticisms of

\footnotetext{
${ }^{45}$ Ibid., p. 11.

46 A. Einstein, “Autobiographical Remarks", in P. A. Schilpp. (ed.) Albert Einstein: Philosopher-Scientist (La Salle, Illinois: Open Court, 1949), p. 17.

${ }^{47}$ R. Penrose, The Road to Reality (London: Jonathan Cape, 2004).
} 
the received body of knowledge. All this tends to reduce education to a kind of intellectual indoctrination, and serves to kill "holy curiosity". Officially, courses in universities divide up into those that are vocational, like engineering, medicine and law, and those that are purely educational, like physics, philosophy or history. What is not noticed, again through insensitivity to problematic aims, is that the supposedly purely educational are actually vocational as well: the student is being trained to be an academic physicist, philosopher or historian, even though only a minute percentage of the students will go on to become academics. Real education, which must be open-ended, and without any pre-determined goal, rarely exists in universities, and yet few notice. ${ }^{48}$

I might add that the hierarchical conception of science indicated above does better justice to the scientific quest for understanding than does orthodox standard empiricist views - and thus does better justice to the value of science pursued for its own sake. ${ }^{49}$

In order to enhance our understanding of persons as beings of value, potentially and actually, we need to understand them empathically, by putting ourselves imaginatively into their shoes, and experiencing, in imagination, what they feel, think, desire, fear, plan, see, love and hate. For wisdom-inquiry, this kind of empathic understanding is rational and intellectually fundamental. Articulating problems of living, and proposing and assessing possible solutions is, we have seen, the fundamental intellectual activity of wisdom-inquiry. But it is just this that we need to do to acquire empathic understanding. Social inquiry, in tackling problems of living, is also promoting empathic understanding of people. Empathic understanding is essential to wisdom. Elsewhere I have argued, indeed, that empathic understanding plays an essential role in the evolution of consciousness. It is required for cooperative action, and even for science. ${ }^{50}$

Granted knowledge-inquiry, on the other hand, empathic understanding hardly satisfies basic requirements for being an intellectually legitimate

\footnotetext{
${ }^{48}$ These considerations are developed further in my What's Wrong With Science?, op. cit.; From Knowledge to Wisdom, op. cit.; and Is Science Neurotic?, op. cit.

${ }^{49}$ See my The Comprehensibility of the Universe, op. cit., chs. 4 and 8; Is Science Neurotic?, op. cit., ch. 2.

${ }^{50}$ For a fuller exposition of such an account of empathic understanding see my From Knowledge to Wisdom, op. cit., $1^{\text {st }}$ ed., pp. 171-189 and ch. 10; $2^{\text {nd }}$ ed., pp. 194-213, and ch. 10; and The Human World in the Physical Universe, op. cit., chs. 5-7 and 9.
} 
kind of explanation and understanding. ${ }^{51}$ It has the status merely of "folk psychology", on a par with "folk physics". Here again, wisdom-inquiry does better justice to inquiry pursued for its own sake than does knowledge-inquiry. ${ }^{52}$

After the publication of From Knowledge to Wisdom in 1984, I published a number of summaries of the argument, striving always to put the argument over in as fresh, lucid and convincing a way as possible. ${ }^{53}$

In 1998 I published The Comprehensibility of the Universe, which spells out in some detail the argument for aim-oriented empiricism, and considers implications of the view for theoretical physics. I argue that aim-oriented empiricism solves a range of fundamental problems in the philosophy of science which cannot be solved within the framework of standard empiricism, including the problem of induction, the problem of verisimilitude, and the problem of simplicity, or unity, of theory. The latter problem is one that I had racked my brains over ever since 1972, when aim-oriented empiricism first occurred to me. I only began to solve the problem when I appreciated that simplicity, or unity, refers, not to the axiomatic structure or form of a theory, but to its content, to what the theory says about the world. For unity, we require that a theory asserts precisely the same for all the phenomena to which the theory applies. Given that a theory makes somewhat different assertions about different ranges of phenomena, degrees of disunity can arise depending on how different, how seriously different, these different assertions are. ${ }^{54}$

\footnotetext{
${ }^{51}$ See From Knowledge to Wisdom, op. cit., $1^{\text {st }}$ ed., pp. 183-189; $2^{\text {nd }}$ ed., pp. 206-213.

52 For my responses to further objections, see Ibid., ch. 8; Is Science Neurotic?, pp. 121-147; and From Knowledge to Wisdom (2007), ch. 13.

${ }^{53}$ For the best of these short expositions, see "What Kind of Inquiry Can Best Help Us Create a Good World?, op. cit.; "Can Humanity Learn to become Civilized? The Crisis of Science without Civilization", op. cit.; "Two Great Problems of Learning", Teaching in Higher Education 8 (January 2003), pp. 129-34; "Do Philosophers Love Wisdom?", op. cit.; "A Revolution for Science and the Humanities: From Knowledge to Wisdom", Dialogue and Universalism, XV;1-2 (2005), pp. 29-57; "Philosophy Seminars for Five-Year-Olds", Learning for Democracy, 1;2 (2005), pp. 71-77 (reprinted in Gifted Education International, 22;2/3 (2007), pp. 122-7); "From Knowledge to Wisdom: The Need for an Academic Revolution", op. cit; "Do We Need a Scientific Revolution?", op. cit.

${ }^{54}$ For details see The Comprehensibility of the Universe, op. cit., chs 3 and 4; Is Science Neurotic?, op. cit., appendix, section 2; and From Knowledge to Wisdom (2007), ch. 14.
} 
My exposition and defence of aim-oriented empiricism and wisdominquiry is further elaborated in Is Science Neurotic? and in chapters 6 and 12 to 14 of the second edition of From Knowledge to Wisdom.

\section{The Human World/Physical Universe Problem (HWPhU Problem)}

I turn now to spelling out what I have done in connection with my first problem - the problem of how it is possible for there to be life of value (the human world as we experience it) embedded in the physical universe. I summarize what I have done in 37 numbered points.

1. We should seek to solve the most severe version of the problem. No attempt should be made to make the problem less severe by espousing antirealist interpretations of physics, behaviourist views about inner experiences, or subjectivist views about what is of value. ${ }^{55}$

2 . The problem is generated by physicalism - the doctrine that the world is made up entirely of fundamental physical entities interacting in accordance with some unified pattern of physical law. Physicalism may be false, but in what follows physicalism is assumed to be true, and the task is to see whether justice can be done to what seems to be most characteristic and of value in our human world granted the truth of physicalism. ${ }^{56}$

3. An early and massively influential attempted solution is Cartesian dualism. Granted Cartesian dualism, the HWPhU problem tends to reduce to two problems: (1) what is the relationship between mind and brain? (2) How can mind influence the brain - required for free will? Even philosophers who reject Cartesian dualism tend to concentrate attention on these two problems. It is vital, however, to return to, and give priority to, the more general, more fundamental HWPhU problem - the problem which Cartesian dualism fails to solve. (1) and (2) need to be put into the broader, more fundamental context of the HWPhU problem. ${ }^{57}$

4. This needs to be done because the solutions to (1) and (2) require it. Thus, in order to solve the mind/brain problem we need, initially, to turn our backs on the mental and consider very carefully the nature of the

\footnotetext{
${ }^{55}$ The Human World in the Physical Universe, op. cit., p. 6.

56 "Physics and Common Sense", op. cit.; From Knowledge to Wisdom, ch. 10; The Human World in the Physical Universe, pp. 5-6.

${ }^{57}$ From Knowledge to Wisdom, op. cit., $1^{\text {st }}$ ed., pp. 260-264, $2^{\text {nd }}$ ed., pp 280-285; The Human World in the Physical Universe, p. 5 and p. 97.
} 
physical. Furthermore, we need to take seriously that non-physical, perceptual properties, such as colours, exist objectively in the world. Such considerations arise naturally within the context of the HWPhU problem, but do not within the context of the mind/brain problem. The brainprocess theory of inner experiences that emerges has a major impact on how the problem of free will is conceived. ${ }^{58}$

5. The crucial step that one needs to take in order to solve the $\mathrm{HWPhU}$ problem is to recognize that physics seeks only to provide the means (in principle) for a complete description of the world of a very special type. A complete physical description of the world would not, in other words, be a complete description. The silence of physics about experiential, human and evaluative features of things - such as perceptual properties of things external to us, inner experiences, the meaningful and evaluative, provides no grounds whatsoever for holding that such things do not exist - just as long as it can be shown that these are the kind of features of things physics does not seek to describe. ${ }^{59}$

6. Physics is concerned only with what may be called the causally efficacious aspect of things. Given any isolated system, physics seeks only to describe that aspect of it which determines necessarily (but possibly only probabilistically) subsequent states of the system when described in the same terms. All non-causally efficacious features of things, such as experiential and value-laden features, will receive no mention whatsoever by the complete physical description, although physical correlates of these features will be described. ${ }^{60}$

7. More specifically, a basic aim of theoretical physics is to discover a theory, $\mathrm{T}$, which is true, unified, applicable in principle to all phenomena, and such that, given any isolated system, $\mathrm{S}$, it provides the means for a true description of the state of $\mathrm{S}$ at any instant such that this description implies true descriptions of subsequent states of the system, couched in the same terms. (This characterization of the aim of theoretical physics needs to be improved in various ways to take into account such things as probabilism,

\footnotetext{
${ }^{58}$ From Knowledge to Wisdom, $1^{\text {st }}$ ed., pp. 260-264, $2^{\text {nd }}$ ed., pp. 280-285; The Human World in the Physical Universe, p. 97, pp. 141-142 and 155-156.

59 "Physics and Common Sense", op. cit.; "Can there be Necessary Connections between Successive Events?". op. cit.; "Understanding Sensations", op. cit.; From Knowledge to Wisdom, op. cit., ch 10; The Human World in the Physical Universe, ch. 5.

${ }^{60}$ As in previous note.
} 
the non-existence of isolated systems, field theory, special and general relativity and quantum theory. I here ignore these complications, as they do not affect the basic point being made concerning the inherent incompleteness of even a complete physics.) This requires that $\mathrm{T}$ is true when interpreted "essentialistically", as attributing necessitating properties to fundamental physical entities (or the fundamental physical entity). T provides the means for a complete or comprehensive description of the world in two senses. First, T applies to any isolated system. Second, T refers to everything that needs to be referred to in order to carry out the predictive task just indicated. But this does not mean that the predictive description, couched in the terms of $\mathrm{T}$, describes all that there is. If the isolated system in question includes a person who perceives colours, sounds and smells, has inner experiences, thinks thoughts and utters or writes meaningful sentences, then none of this will be included in the predictive description provided by $\mathrm{T}$ (although physical correlates of these things will be included) just as long as this omission does not interfere with the predictive task indicated above. ${ }^{61}$

8. A key element of this proposal is that theoretical physics seeks to characterize "necessitating properties" of fundamental physical entities, and does not just specify laws or regularities in phenomena. It requires a thoroughly anti-Humean account of causation. It requires that necessary connections between successive states of affairs are possible - a point I argued for in my MA thesis and second published paper (1968a). It also requires, not just scientific realism but, rather more strongly, scientific essentialism. In order to be ultimately acceptable, physical theories must be amenable to essentialistic interpretation. This in turn requires that a fully micro-realist, essentialist version of quantum theory needs to be developed - something I have sought to supply with my work on "propensiton" quantum theory. Essentialistic probabilism is, I argue, the key to making sense of the quantum domain. I put forward such a version of quantum theory: it is fundamentally probabilistic, fully micro-realistic, able to recover all the empirical success of orthodox quantum theory, and yet empirically distinct from that theory for experiments not yet performed. $^{62}$

\footnotetext{
${ }^{61}$ Ibid., plus "The Mind-Body Problem and Explanatory Dualism" op. cit.

${ }^{62}$ For conjectural essentialism see my "Can there be Necessary Connections between Successive Events?", op. cit.; The Comprehensibility of the Universe, op. cit., pp. 141-
} 
9. Recognizing clearly what it is physics aims to do - so that a complete physical description of the world would not be a complete description solves a fundamental mystery about consciousness and the experiential. In seeking to understand consciousness, we may invoke the best mode of understanding available, namely scientific understanding. But when we do this, and explore what goes on inside our heads scientifically, we learn much about such things as neurons, synaptic junctions, exchange of sodium and potassium ions and so on, but never seem to encounter anything remotely like a thought, a feeling, an inner sensation, a moment of conscious awareness, as we experience these things. Before the gaze of science, consciousness seems to evaporate; it seems to become a profound mystery, utterly resistant to scientific explanation and understanding. But once we have grasped the above account of what physics, and all of natural science in principle reducible to physics, aims to achieve, it is clear that the fact that the scientific account of what goes inside our heads tells us nothing about consciousness as we experience it does not mean consciousness is inherently and profoundly mysterious. It just means that the experiential aspect of what goes on inside our heads is of no interest to physics because no reference needs to be made to it to complete the predictive task of physics. Consciousness and the experiential evade physical explanation, not because they are inherently mysterious, but because they are, from the standpoint of physics, entirely without interest, irrelevant to the task in hand. ${ }^{63}$

10. But might not it be possible for physics to describe experiential aspects of things? A simple argument establishes that the answer is "no". In order to know what sort of property redness as we perceive it is, one must oneself have at some stage in one's life have perceived red things, or at least experienced the visual sensation of redness. Simply in order to know

155. For an account of my development of essentialistic quantum theory, and references to relevant publications see note 3 above. See also "Are Probabilism and Special Relativity Incompatible?", Philosophy of Science, 52 (1985), pp. 23-43; "Does Orthodox Quantum Theory Undermine, or Support, Scientific Realism?", The Philosophical Quarterly 43 (1993), pp. 139-57; The Comprehensibility of the Universe, op. cit. ch. 7; "Does Probabilism Solve the Great Quantum Mystery?", Theoria, 19/3; 51 (2004), pp. 321-36.

${ }^{63}$ See "Understanding Sensations", op. cit.; From Knowledge to Wisdom, op. cit., $1^{\text {st }}$ ed., pp. 261-267, $2^{\text {nd }}$ ed., pp. 282-288; "The Mind-Body Problem and Explanatory Dualism" op. cit.; The Human World in the Physical Universe, ch. 5. 
what "roses are red" means (where "red" refers to the perceptual property), one must oneself have had the visual sensation of redness - which we may take to mean that one has had occur in one's brain a particular kind of brain process. A person colour-blind, or blind, from birth, cannot know what redness is. But such a person is not thereby debarred from understanding all of physics, just as well as any sighted person. Such a person is not debarred from understanding everything implied by physics which means no purely physical description can imply "This is red", where "red" is understood to refer to the experiential or perceptual property. (The colour-blind person can understand everything implied by physics, but cannot understand "This is red"; hence "This is red" cannot be implied by physics.) Not only does physics not need to refer to redness; it cannot do so. This argument does not establish that redness exists, it just establishes that the silence of physics about redness - and endless other experiential and value-laden features of things - provides no grounds whatsoever for supposing that such features do not really exist. ${ }^{64}$ This is the argument, first spelled out by me in 1966 and $1968{ }^{65}$ which, wrenched out of context, received a great deal of subsequent attention as a result of subsequent publications of Thomas Nagel ${ }^{66}$ and Franck Jackson, ${ }^{67}$ eight and twenty years later. ${ }^{68}$ Closely related theses of experiential physicalism have not, unfortunately, received a similar degree of attention. I still hope that, one day, philosophers might come to consider, not just this argument, but the thesis of, and arguments for, experiential physicalism as a whole.

11. Might not postulates be added to the true physical theory of everything, $\mathrm{T}$, linking physical and experiential features, so that a new theory, $\mathrm{T}^{*}$, is arrived at, genuinely complete and comprehensive, capable of predicting and explaining experiential features in additional to physical features,

64 Physics and Common Sense: A Critique of Physicalism, op. cit.; "Physics and Common Sense", op. cit.; "Understanding Sensations", op. cit.; From Knowledge to Wisdom, op. cit., pp. 262-263, $2^{\text {nd }}$ ed., pp. 283-284; “The Mind-Body Problem and Explanatory Dualism" op. cit.; The Human World in the Physical Universe, ch. 5.

65 "Physics and Common Sense", op. cit.; "Understanding Sensations", op. cit.

66 T. Nagel, "What Is It Like to Be a Bat?", op. cit.

${ }^{67}$ F. Jackson, "What Mary Didn't Know", op. cit.

${ }^{68}$ When I drew Thomas Nagel's attention to my papers of 1966 and 1968 he wrote in a letter, with great generosity "There is no justice. No, I was unaware of your papers, which made the central point before anyone else." Jackson acknowledged, however, that he had read my 1968 paper before writing his. 
unlike T? Such a theory, $\mathrm{T}^{*}$, would be so horrendously complex and ad hoc that, even though predictive, it would not be explanatory. Each correlating postulate would be horrendously complex. Given the complexities of colour vision, it is clear that the postulate specifying physical correlates of the perceptual property "red" would be almost inconceivably complex. And given what we may presume to be the complexity and variety of brain processes that correlate with the visual experience of redness, we may assume that the postulate specifying physical correlates of the visual experience of redness would also be extraordinarily complex. Furthermore, when one takes into account the great number and variety of non-physical experiential and personalistic features of things, actual and potential, associated with human beings, other sentient animals and beings, actual and possible, it becomes clear that there would be a vast number of additional postulates associated with $\mathrm{T}^{*}$, each one of which would be incredibly complex. $T^{*}$ would be so complex and $a d$ hoc as to be entirely non-explanatory. Here, in other words, is the explanation as to why physics eschews all reference to the experiential: physics must do this in order to develop the powerfully explanatory theories that it does develop. Physics fails to explain the experiential, not because the experiential is inherently mysterious and inexplicable, but rather because excluding all reference to the experiential is the price that must be paid to have the astonishingly explanatory theories of physics that we do have. ${ }^{69}$

12. Two rival theories of perception need to be distinguished, which may be called internalism and externalism. According to internalism, what we directly perceive, what we directly know about in perception, is our inner experiences: knowledge of external objects is inferred, somewhat shakily, from our immediate knowledge of our inner experiences. According to externalism, it is exactly the other way round. What we directly perceive, what we directly know about in perception, is what we ordinarily assume we perceive, objects external to us, tables, trees and houses; our knowledge of our inner sensory experiences is inferred, somewhat shakily, from our immediate knowledge of objects external to us.

13. Physicalism may seem to imply internalism, for at least two reasons.

${ }^{69}$ See my From Knowledge to Wisdom, op. cit., $1^{\text {st }}$ ed., pp. 263-264, $2^{\text {nd }}$ ed., pp. $284-$ 285; "The Mind-Body Problem and Explanatory Dualism", op. cit., pp. 64-65; The Human World in the Physical Universe, pp.119-121. 
First, the silence of physics about perceptual properties may be taken to mean that they do not exist, and hence externalism cannot be correct because what we ordinarily assume we know about objects external to us in perception is almost entirely false. Second, physicalism applied to perception may seem to imply internalism, because it implies that a complex chain of processes links the external object to our perceptual experience of it: light is reflected from the object, enters our eyes, activates cells in our retina which cause neurons of the optic nerve to fire, which in turn cause vast numbers of neurons in the brain to fire, eventually leading to the experience of seeing the external object. What we really know about is the last event in this chain of events, namely the inner perceptual experience. From that we infer (shakily) our knowledge about the external object. $^{70}$

14. Both arguments are invalid. The first has already been shown to be invalid. The second is invalid because the existence of the chain of events provides no grounds whatsoever for holding that what we directly see and really know about in perception is the last event in the chain of events associated with perception. What we directly perceive is what we primarily know about in perception, and that, we may argue, is what we ordinarily assume we know about in perception, external perceived objects (when we are not suffering from illusions or hallucinations). That a chain of events exists between the perceived object and our brain does not mean that what we directly perceive is the last event in the chain. On the contrary, we do not perceive our inner experiences at all. Our knowledge of our inner perceptual experiences is derived from our more direct, primary knowledge of perceived objects external to us. If I have the experience of seeing a red rose, what I know about this experience is merely: something is going on inside me which is the sort of thing that goes on when I see a red rose. ${ }^{71}$

15. We may adopt the view, in short, that colours, sounds and other perceptual qualities are real, objective properties of things in the world around us, and we know about these qualities as a result, and only as a result, of perceiving these things. Objectivism about perceptual qualities,

\footnotetext{
70 "Physics and Common Sense", op. cit., pp. 300-301; The Human World in the Physical Universe, pp. 75-76.

71 "Physics and Common Sense"; "Understanding Sensations"; "The Mind-Body Problem and Explanatory Dualism"; The Human World in the Physical Universe, pp. 98-100.
} 
and externalism, are linked together, just as subjectivism about perceptual qualities, and internalism, are linked together. ${ }^{72}$

16. But can it really be the case that colours (and other perceptual qualities) are objective? In one sense of objective, yes, in another sense, no. If by objective we mean "really existing in the external world", then what the above arguments have shown is that we have every reason to believe colours are objective, and no reason to believe that they are not. But if by objective, we mean capable of being known about whatever your sense organs and brain may be like, then the answer must be no, colours are not objective. In order to see and know about colours, as we noncolour-blind humans perceive them, you must have the physiology of a non-colour-blind human being. Aliens, with brains so different from ours that brain processes that are colour experiences cannot occur in them, cannot know what red, blue, green, as experienced by us, are. In this second sense, colours are subjective, not objective. Colours are, I argue, objective in the first sense, subjective in the second sense. They exist out there in the world, but can only be known about by beings sufficiently like ourselves $^{73}$

17. The transition from internalism to externalism has dramatic consequences for the mind/brain problem. Internalism implies that we directly "see" and know about our inner experiences. But these inner perceptual experiences - of red roses, green trees and blue skies - are clearly utterly different from all processes going on in the brain (firing of neurons, etc.). Internalism all but forces us to adopt some version of dualism which postulates mental entities or processes utterly distinct from neurological or physical processes going on in the brain. All this is changed profoundly the moment externalism is adopted. For, according to externalism, we simply do not ordinarily know enough about our inner experiences to exclude the possibility that these inner experiences are brain processes. Given the known intimate connections between inner experiences and brain processes, the obvious conjecture to adopt, once externalism is accepted, is that our inner experiences are brain processes -

\footnotetext{
72 "Physics and Common Sense"; "Understanding Sensations"; From Knowledge to Wisdom, op. cit., $1^{\text {st }}$ ed., pp. 251-252, $2^{\text {nd }}$ ed., pp. 273-274; "The Mind-Body Problem and Explanatory Dualism"; The Human World in the Physical Universe, pp. 97-121.

73 "Physics and Common Sense", pp. 310-311; "The Mind-Body Problem and Explanatory Dualism", pp. 56-57; The Human World in the Physical Universe, pp. 3437 and 112-119.
} 
or "head processes" as they may be called, to adopt neutral terminology between the physical and the experiential. ${ }^{74}$

18. Head processes, it may be held, have two aspects: physical and experiential. The experiential aspect of a head process is what one learns about when a sufficiently similar head process occurs in one's own brain. This is what the experiential aspect of a head process is - this and no more. $^{75}$

19. A complete physical description of a conscious brain would be entirely silent about consciousness, about the experiential aspects of the physical processes going on in the brain, for exactly the same reason as a complete physical description of a tree would be silent about the greenness of its leaves: experiential features of brain processes, and perceptual features of leaves, are entirely without interest to physics. No reference to them is needed for the predictive task of physics to proceed, and no reference can be made if physical theory is to be explanatory. ${ }^{76}$

20. This is a version of the identity thesis. It requires that Kripke's (very weak) arguments concerning contingent identity with rigid designators are invalid. I have shown that Kripke's arguments are indeed invalid. ${ }^{77}$

21. This two-aspect version of the identity thesis has dramatic consequences for the free will/physicalism problem. It means that mental processes, such as decisions to act, can play a crucial causal role in the production of the intended action because these mental processes are also physical processes occurring in the brain. The Cartesian nightmare as to how the mind can influence the brain disappears because the mind is the brain. $^{78}$

22. Even though the experiential cannot be understood scientifically (for perfectly understandable reasons), it can be understood personalistically a distinct kind of explanation and understanding as fundamental, in its own

\footnotetext{
74 "Physics and Common Sense"; "Understanding Sensations"; From Knowledge to Wisdom, $1^{\text {st }}$ ed., pp. 259-264, $2^{\text {nd }}$ ed., pp. 280-285; The Human World in the Physical Universe, pp. 97-103 and 112-119.

75 "Physics and Common Sense"; "Understanding Sensations"; The Human World in the Physical Universe, pp. 117-119.

76 "Physics and Common Sense"; "Understanding Sensations"; From Knowledge to Wisdom, op. cit., $1^{\text {st }}$ ed., pp. 261-264, $2^{\text {nd }}$ ed., pp. 281-285; "The Mind-Body Problem and Explanatory Dualism"; The Human World in the Physical Universe, ch. 5.

${ }^{77}$ Ibid., Appendix 3.

${ }^{78}$ Ibid., pp. 141-142.
} 
way, as scientific understanding. I understand another personalistically if I can, in imagination, see, feel, experience, desire, fear, believe what the other person sees, feels, etc. I must experience, in imagination, what the other person desires and fears, what he seeks, what he sees as his problems, and what actions he considers taking to solve these problems. ${ }^{79}$

23. Granted knowledge-inquiry, personalistic explanations do not qualify as genuine explanations; they reduce to "folk psychology" to be replaced by authentic explanations when psychology and neuroscience have advanced sufficiently to provide them. Granted the more rigorous wisdom-inquiry, however, personalistic explanations are intellectually fundamental, being associated with the intellectually fundamental tasks of articulating problems of living, and proposing and critically assessing possible solutions. ${ }^{80}$

24. Viewed from a scientific perspective, the experiential domain (consciousness, mental features of brain processes, perceptual qualities) seems utterly mysterious and inexplicable because it seems inherently beyond the scope of scientific explanation and understanding. This inherent apparent scientific inexplicability of consciousness and the experiential is, I claim, close to the nub of the mind/brain problem and, more generally, the HWPhU problem. The viewpoint sketched here experiential physicalism - solves this part of the problem by (a) explaining why it is that science cannot explain the mental, the experiential (points 9 and 10 above), and (b) demonstrating that consciousness, the experiential, can be genuinely explained and understood by means of intellectually authentic personalistic explanation and understanding. That part of the experiential that we can ourselves experience is, potentially, fully intelligible and understandable personalistically to us. But point (b) only goes through if the arguments for wisdom-inquiry are valid. Granted knowledge-inquiry, personalistic explanation is merely folk psychology; its explanations are intellectually spurious and illusory. But grant wisdominquiry instead, and personalistic explanation becomes intellectually genuine, an authentic mode of explanation that cannot be eliminated or replaced. The experiential can indeed be genuinely understood by its

${ }^{79}$ From Knowledge to Wisdom, op. cit., $1^{\text {st }}$ ed., pp. 174-189 and 264-273, $2^{\text {nd }}$ ed., pp. 197-213 and 285-294; The Human World in the Physical Universe, pp. 103-112.

${ }^{80}$ From Knowledge to Wisdom, op. cit., $1^{\text {st }}$ ed., pp. 183-189, $2^{\text {nd }}$ ed., pp. 206-213; The Human World in the Physical Universe, pp. 109-110. 
means. Here is one way in which my proposed solution to the "wisdominquiry problem" has a major impact on my proposed solution to the mind/brain problem and the more general HWPhU problem. ${ }^{81}$

25. Personalistic understanding can be of intrinsic value; it makes possible friendship, intimacy and love; it enables us to become acquainted with what is of value in the lives of others. Unlike good scientific explanation, personalistic explanation does not provide reliable prediction, and is thus not a reliable tool for manipulating people. Instead, it is essential for cooperation. $^{82}$

26. Personalistic understanding is essential for science. In seeking to acquire personalistic understanding of another, we may have two rather different motives: we may want to understand the person, or we may want to improve our knowledge and understanding of the world, and we seek to discover what the other person believes about the world because we hope this will contribute to our own knowledge. Science is the outcome of a multitude of such acts of personalistic understandings between scientists, with the personal dimension largely suppressed. Communication by means of language, meaningful sentences, propositions, and thus theories too, presuppose and are an elaboration of personalistic understanding. ${ }^{83}$

27. Grice showed that human communication involves multi-layered interactions and acts of mutual understanding. This can be understood as evolving, layer by layer, from elementary, one-layered, accidental animal communication. $^{84}$

28. A basic task for neuroscience is to discover what the neurological correlates of consciousness are - how, that is, personalistic and neurological (i.e. scientific) accounts of what goes on inside our beads are correlated. This task must appeal to both scientific and personalistic modes of explanation. The personalistic cannot be reduced to the neurological (i.e. the scientific). ${ }^{85}$

29. A basic first step is to locate consciousness in the brain - i.e. to identify

${ }^{81}$ From Knowledge to Wisdom, op. cit., $1^{\text {st }}$ ed., pp. 261-273, $2^{\text {nd }}$ ed., pp. 281-294; The Human World in the Physical Universe, chs. 5 and 7.

${ }^{82}$ From Knowledge to Wisdom, $1^{\text {st }}$ ed., pp. 185-189, $2^{\text {nd }}$ ed., pp. 208-213; The Human World in the Physical Universe, pp. 108-109.

${ }^{83}$ From Knowledge to Wisdom, $1^{\text {st }}$ ed., pp. $188-189$ and $264-267,2^{\text {nd }}$ ed., pp. $210-213$, and 285-288; The Human World in the Physical Universe, pp. 110-111.

${ }^{84}$ Ibid., pp. 189-190.

${ }^{85}$ See Ibid., ch. 8 . 
neurological processes that are conscious processes (as opposed to neurological processes that support, that are necessary for but are not identical to, conscious processes). I conjecture that consciousness is to be identified with neurological processes occurring in the mid brain (the limbic system) together with whatever neurological processes happen to be in strong two-way interaction with the mid brain. This hypothesis - a modification of a hypothesis put forward by Wilder Penfield, ${ }^{86}$ Donald McKay, ${ }^{87}$ and Francis Crick ${ }^{88}$ - can do justice to the key function of animal consciousness: to guide the animal in its changing environment so that it acts in such ways conducive to survival and reproductive success. In the case of humans, the hypothesis can do justice both to the persistence, the continuity, of consciousness, and to its immense variability and variety of content, involving as it does perception, imagination, emotion, desire, thought, and volition - the initiation and control of action. ${ }^{89}$

30. Why are brain processes and sensations correlated in the way that they are? No one has been able to think of even a possible explanation. My proposal is this. Our sensations - of sight, sound, smell, touch - are isolated, widely separated, minute patches in a vast, smoothly varying, multidimensional space of all possible sensations. The points of this space can be put together in only one way so as to preserve experiential "smoothness", so that as one moves through the space, sensations vary smoothly, like a sound, of fixed timbre and loudness varying smoothly as the pitch is continuously varied. This smoothly varying space of all possible sensations can only be correlated with smoothly varying, functionally described brain processes in one way (so as to preserve smoothness in both experienced sensation and corresponding functionally described brain process). It is this unique matching which provides the

\footnotetext{
${ }^{86}$ W. Penfield, "The cerebral cortex in man. 1. The cerebral cortex and Consciousness", Arch. Neurol. and Psychiat. 40 (1938), pp. 417-442; The Excitable Cortex in Conscious Man (Liverpool: Liverpool University Press, 1958); The Mystery of the Mind (Princeton: Princeton University Press, 1975).

${ }^{87}$ D. MacKay, "Cerebral Organization and the Conscious Control of Action", in J. Eccles, (ed.), Brain and Conscious Experience (Berlin: Springer-Verlag, 1966), pp. 422-445 and 312-313; "Divided Brains, Divided Minds?" in C. Blakemore and S. Greenfield, (eds.), Mindwaves (Oxford: Blackwell, 1987), pp. 5-16.

${ }^{88}$ F. Crick, "Function of the thalamic reticular complex: The searchlight hypothesis", Proceedings of the National Academy of Sciences USA 81 (1984), pp. 4586-4590.

${ }^{89}$ The Human World in the Physical Universe, ch. 8 .
} 
explanation for the fact that the sensations we experience are correlated in the specific way that they are with corresponding neurological processes occurring in our brain. Any other correlations would violate the unique smoothness-preserving mapping from the space of all possible sensations to the space of all possible sensory brain processes. ${ }^{90}$

31. Human beings (and other sentient animals) are intelligible simultaneously in two ways: personalistically and physically. I propose a compatibilist solution the free will/ physicalism problem, the nub of which claims that, for free will, we require that freedom-ascribing personalistic explanations of human actions are both true and compatible with physical explanations (counterfactuals implied by these two kinds of explanation all being true). That this kind of double comprehensibility exists is possible but almost miraculous. Compatibilism, in order to be acceptable, must provide an explanation for this apparent miracle. ${ }^{91}$

32. In order to do this, a third kind of explanation needs to be invoked: purposive explanation. This is applicable to any goal-pursuing entity, whether sentient or not, and explains actions as being designed to realize goals of the entity in question in the given environment. It is applicable to all living things, to thermostats, guided missiles and robots. The atom of purposiveness is the feedback mechanism. ${ }^{92}$

33. Darwinian theory needs to be interpreted in such a way that it helps explain how and why purposive life has evolved and proliferated (and should not be interpreted as explaining apparent purposiveness away). Darwin is an exemplary philosopher, in that he helps to solve the fundamental problem of how purposive beings, namely living things, can have come to exist in a purposeless universe, in an extraordinarily fruitful way. The idea that Darwinian theory, interpreted as being about the evolution of purposive living things, can help us understand human history and aspects of our human world, is sketched, as "the generalized Darwinian Research Programme", in From Knowledge to Wisdom, and elaborated subsequently in The Human World in the Physical Universe. ${ }^{93}$

\footnotetext{
90 The Human World in the Physical Universe, pp. 126-129; "Three Problems about Consciousness and their Possible Resolution", PMS WIPS 005 (November 15), http:/www.petemandik.com/blog/pms-wips/ .

${ }^{91}$ The Human World in the Physical Universe, ch. 7 .

${ }^{92}$ From Knowledge to Wisdom, $1^{\text {st }}$ ed., pp. 267-269, $2^{\text {nd }}$ ed., pp. 288-289; The Human World in the Physical Universe, pp. 130-131.

${ }^{93}$ See From Knowledge to Wisdom, $1^{\text {st }}$ ed., pp. 269-275, $2^{\text {nd }}$ ed., pp. 290-296; and The
} 
34. Reinterpretation of Darwinian theory is required in order that the theory should help explain the existence, the evolution, of sentience and consciousness. This reinterpretation emphasizes that the mechanisms of evolution themselves evolve as evolution proceeds, gradually acquiring purposive and personalistic aspects, via unconscious animal breeding (offspring, sexual, and prey and predator selection), and cultural evolution (based on individual learning and imitation). I have proposed a number of key stages in the evolution of sentience and consciousness, from active and motivational control to the emergence of imagination, personalistic understanding and language..$^{94}$

35. Human evolution has created fundamental new problems of living: discovery of death; dramatic changes in environment and way of life; clash of control systems (conscious and long-term); science without wisdom. ${ }^{95}$

36. I defend the view that what is of value exists objectively as a part of the fabric of the human world, and rebut metaphysical, moral and epistemological objections to this thesis of value-realism. What is of value, I conjecture, is living life lovingly - or what comes into existence when we live life lovingly. ${ }^{96}$

37. I put forward an argument for the reality of free will. First, wisdom, construed as the capacity to realize what is of value in life (for oneself and others) is a stronger notion than free will, in that it implies but is not implied by free will. Second, what poses a threat to the reality of wisdom or free will is the picture of the universe that emerges from modern natural science (physicalism). But if science, as construed by aim-oriented empiricism, is broadly correct, then we have achieved something of undeniable and great value: we have immensely enhanced our knowledge and understanding of the world. Thus, that which threatens to annihilate free will actually demonstrates its reality. Either modern science is broadly correct, in which case free will exists, or it is not, in which case the threat

Human World in the Physical Universe, ch. 7. See also From Knowledge to Wisdom, $1^{\text {st }}$ ed., pp. 174-181, $2^{\text {nd }}$ ed., pp. 197-205; and "Methodological Problems of Neuroscience", op. cit.

${ }_{94}^{94}$ The Human World in the Physical Universe, ch. 7.

95 The Human World in the Physical Universe, pp. 190-192. See, too, From Knowledge to Wisdom, $1^{\text {st }}$ ed., pp. 193-195, $2^{\text {nd }}$ ed., pp. 216-218.

${ }^{96}$ From Knowledge to Wisdom, ch. 10; The Human World in the Physical Universe, ch. 2. 
to free will disappears. ${ }^{97}$

\section{Connections Between the Two Problems}

That there is a connection between the two problems is immediately obvious. The problem "What kind of inquiry can best help life of value to flourish in the physical universe?" hardly arises unless there is a solution to the problem "How is life of value possible in the physical universe?". But this connection is even tighter than one might at first suppose. Aimoriented empiricism, it will be remembered, is the conception of science at the core of wisdom-inquiry; it is the first step of the second argument in support of wisdom-inquiry. But, according to aim-oriented empiricism, physicalism is a basic tenet of (conjectural) scientific knowledge. It is more secure, indeed, than any accepted physical theory, such as Newtonian theory, quantum theory or general relativity. For theories which clash with physicalism too severely are rejected, whatever their empirical success might be; and even accepted theories are held to be false, whatever their empirical success, because they clash with physicalism. (Science might, one day, reject physicalism, but this would constitute a major revolution comparable to the one that initiated modern science.)

Thus, the argument for wisdom-inquiry has the paradoxical consequence that, in establishing physicalism as a rather secure item of scientific knowledge, it calls into question the very possibility of there being life of value in the world at all. Clearly, a solution to the HWPhU problem is required if the argument for wisdom-inquiry is to have any coherence whatsoever. The solution I propose to the HWPhU problem, just indicated, makes viable the arguments I have sketched in support of wisdom-inquiry.

A second connection has to do with the problem of simplicity or unity, and the meaning of physicalism. A great success of aim-oriented empiricism (integral to wisdom-inquiry) is that it solves a long-standing problem in the philosophy of science which baffled even Einstein: ${ }^{98}$ what does it mean to say of a theory that it is unified? My proposed solution leads one to distinguish eight different kinds of unity, which in turn

${ }^{97}$ From Knowledge to Wisdom, $1^{\text {st }}$ ed., pp. 273-274, $2^{\text {nd }}$ ed., pp. 294-295; see, too, The Human World in the Physical Universe, ch. 6.

${ }^{98}$ A. Einstein, "Autobiographical Remarks", op. cit., pp. 21-23. 
correspond to eight different versions of physicalism. A flood of light is thrown on what physicalism can mean, and hence on what creates the HWPhU problem in the first place. ${ }^{99}$

A third connection concerns personalistic explanation and "double comprehensibility". A basic feature of experiential physicalism (the solution I propose to the HWPhU problem) is that it holds that sentient beings are comprehensible in two very different ways: physically, and personalistically. Granted knowledge-inquiry, however, personalistic explanation hardly qualifies as an intellectually legitimate mode of explanation in its own right. It amounts to little more than "folk psychology", to be replaced by something better when psychology advances. Reject knowledge-inquiry, and accept wisdom-inquiry in its place, and the situation is transformed: personalistic explanation becomes intellectually uneliminatable, and certainly not reducible to scientific explanation. Indeed, scientific explanations can only exist because scientists can acquire implicit personalistic understanding of each other. That wisdom-inquiry enormously enhances the intellectual status of personalistic explanation, in this way, enormously strengthens experiential physicalism, considered as a possible solution to the mind/brain problem, and the more general HWPhU problem (as I remarked in point 24 above), and enhances the force and plausibility of the proposed compatibilist solution to the free will/physicalism problem, which depends on personalistic explanation being an authentic mode of explanation in an essential way. ${ }^{100}$

One feature of experiential physicalism is value realism. This may be regarded as giving support to wisdom-inquiry, even though the latter does not depend on value realism.

Finally, wisdom-inquiry and experiential physicalism combine in strongly implying that aims are bound to be, at some point, profoundly problematic, the task of improving aims also being profoundly problematic. Granted physicalism, it is, in any case, little short of a miracle that there exists anything capable of pursuing aims at all, let alone sentient or conscious beings able to pursue aims of value. In considering, at a fundamental level, the nature of the problems that confront us in

\footnotetext{
${ }^{9}$ See my The Comprehensibility of the Universe, chs. 3 and 4; Is Science Neurotic?, Appendix, section 2; From Knowledge to Wisdom (2007), ch. 14.

${ }^{100}$ The Human World in the Physical Universe, ch. 6.
} 
seeking to realize what is of value in life, we need to take into account the manner in which we, and all purposive things, have come to exist in the physical universe. We need, in short, to consider the implications of Darwinian theory, appropriately interpreted.

One immediate implication is that human learning is a development of animal learning. Just as animal leaning is, fundamentally, learning how to live (how to act in pursuit of survival and reproductive success), so too human learning is, fundamentally, learning how to live, how to act. This is, of course, central to wisdom-inquiry. One big difference is that, whereas animals have a given basic aim set by evolution, we humans do not. Our task is to transform the basic aim we have inherited from evolution - survival and reproductive success - into the realization of what is of value, which includes, but goes beyond, mere survival and reproduction. At once a number of points deserve to be made.

First, nothing in evolution equips us to transform the basic aim of survival and reproduction into the aim of realizing what is of value. Evolution designs things capable of pursuing survival and reproduction in an immense variety of ways, but leaves this basic aim fixed. This should alert us, immediately, to the likelihood that we will find it very difficult indeed to transform aims inherited from our evolutionary past into the aim of realizing what is of value. The machinery of aim-oriented rationality, designed specifically to help us do this, is likely to be urgently needed. As it is, aim-oriented rationality has yet to enter public consciousness, despite my thirty years' campaign on its behalf. Our plight is dire indeed. We have not yet appreciated just how fundamentally important and difficult it is progressively to improve our aims in life, personal, social, and institutional - and thus how vital to put in place intellectual/social structures designed to help us do this.

Second, taking into account our evolutionary past and manner of creation, it is all too likely that humanity will misconstrue and misrepresent what its aims are, in an all-pervasive fashion. Darwinian theory is a relatively recent discovery - when put into the context of human history and pre-history. The idea that Darwinian theory is relevant to thought about how we should live and tackle our problems of living is even more recent. Until very recently, in short, a Darwinian understanding of what our basic aims are in life has not been available to us. Aims have been interpreted and understood in all sorts of other terms, religious, cultural, social, personal. Misrepresentation of aims will have been endemic from 
the outset of the possibility of misrepresentation, with the beginnings of culture. All this massively reinforces the first point: the machinery of aimoriented rationality is likely to be urgently needed to help us become more honest about what our aims really are, as a first step towards discovering how our aims can be improved.

Third, our psyches were designed to enable us to pursue survival and reproduction successfully while living in hunting and gathering groups of about 150 to 200 people. Change the conditions of life, and this same psyche may produce actions thoroughly deranged from the standpoint of survival and reproduction. But billions of people living in crowded cities today do indeed live in a world very different from that of hunting and gathering people. This in itself poses problems for the pursuit of survival and reproduction, let alone what is of value in life.

Fourth, and closely connected with this last point, culture makes it possible to interpret evolutionary aims in new, and sometimes newly disastrous, ways. Survival and reproduction, for example, given culture, may receive many diverse interpretations, many thoroughly deranged and leading to deranged pursuits. Thus, given religion, survival may be interpreted to be survival after death: the suicide terrorist may be driven, in part, by the urge to survive. Once again, an evolutionary perspective throws into sharp relief the fundamental importance of employing aimoriented rationality to help us develop our aims in worthwhile directions.

Fifth, humanity, perhaps uniquely among living things, is confronted by the discovery of the inevitability of death. The pursuit of survival is, for each one of us, ultimately doomed. Much of our culture has sought to deny this grim truth. Given that the urge to survive is such a fundamental part of our makeup, the temptations to deny death, in all sorts of ways, will be immense. Once again we see just how important aim-oriented rationality must be. Death ensures that our life aims become, at some point, horribly problematic. We need aim-oriented rationality to help us solve these death-generated problems concerning our aims, insofar as they can be solved, and to help us avoid the temptations of denial and delusion.

Finally, humanity, again uniquely, seeks to plan consciously its way of life, a task for which consciousness was not designed by evolution. Consciousness in mammals, it is reasonable to hold, has the task of deciding, from moment to moment, or at intervals of minutes at the most, what is to be done. It does not plan the way of life. But human beings, as a result of the development of imagination, personalistic understanding and 
culture, can consciously act in a vastly expanded arena, taking in thousands of miles and decades into the future. This will, almost inevitably, lead to a clash between the system of hormones and so on which once controlled our way of life, and our conscious minds. Furthermore, consciousness will not have been equipped by evolution to take on the task of planning the way of life. Once again, aim-oriented rationality will be needed to help resolve conflicts that arise as a result of our evolutionary past.

In short, put human life into the context of experiential physicalism, and Darwinism appropriately interpreted, and it becomes abundantly clear that aim-oriented rationality and wisdom-inquiry need to be built, urgently, into our culture, into our human world. A human world which has had the good sense to take wisdom-inquiry seriously would have the capacity to improve aims as a part of life, and would thus be able to make progress towards a better world. A world without wisdom-inquiry will continue to blunder, I fear, from disaster to disaster, the disasters becoming more serious as our powers to cause havoc become greater and more widely distributed. 